\title{
Contaminant Bioaccumulation Dynamics in Young-of-the- Year Bluefish Subpopulations in New York Bight with a Special Reference to the Condition and Nursery Area Fidelity Subsequent to Recruitment
}

\begin{tabular}{|r|l|}
\hline Journal: & Canadian Journal of Fisheries and Aquatic Sciences \\
\hline Manuscript ID & cjfas-2015-0369 \\
\hline Danuscript Type: & Article \\
\hline Complete List of Authors: & $\begin{array}{l}\text { Deshpande, Ashok; National Marine Fisheries Service - NOAA } \\
\text { Dockum, Bruce; National Marine Fisheries Service - NOAA } \\
\text { Draxler, Andrew; National Marine Fisheries Service - NOAA }\end{array}$ \\
\hline Keyword: & $\begin{array}{l}\text { Young-of-the-year bluefish, New York Bight, PCBs, Pesticides, Nursery- } \\
\text { Fidelity }\end{array}$ \\
\hline \multicolumn{2}{|c}{} \\
\hline
\end{tabular}




\section{Title}

2 Contaminant Bioaccumulation Dynamics in Young-of-the-Year Bluefish Subpopulations in New

3 York Bight with a Special Reference to the Condition and Nursery Area Fidelity Subsequent to

$4 \quad$ Recruitment

5 Authors

6 Ashok D. Deshpande, Bruce W. Dockum, and Andrew F.J. Draxler 
7 Abstract

8 Contaminant bioaccumulation dynamics was examined in young-of-the-year (YOY)

9 bluefish subpopulations (Pomatomus saltatrix) in New York Bight ecosystem, and the results

10 were used to assess: (i) effects of habitat quality in terms of levels of PCBs and pesticides on

11 bluefish condition, and (ii) fidelity of YOY bluefish to different subestuaries which served as the

12 nurseries subsequent to recruitment during their first summer. Total PCBs and p,p'-DDE body

13 burdens increased with fish length, but concentrations generally increased only poorly to

14 moderately, which suggested steady-state contaminant uptake commensurate with aggressive

15 feeding and dilution related to rapid growth characteristic of YOY bluefish within a subestuary.

16 High condition factors paired with elevated contamination levels in bluefish from Lower Hudson

17 River, as compared with bluefish from Newark Bay with poor condition factors paired with

18 elevated contamination levels, suggested that PCBs and pesticides alone may not determine

19 condition in these fish. We found dissimilar patterns of prominent PCB congeners in bluefish

20 from adjacent subestuaries (e.g., Newark Bay and Lower Hudson River) suggesting separate

21 contaminant sources. Total PCB normalized fingerprints of PCB congeners permitted statistical

22 discrimination among YOY bluefish specimens from various estuaries with a potential to

23 differentiate subpopulations on scales to less than $20 \mathrm{~km}$. This unexpected fidelity to nursery

24 estuaries may have implications for the management strategies.

25 Keywords: Young-of-the-year bluefish, New York Bight, PCBs, Pesticides, Nursery-Fidelity 


\section{Introduction}

27 Bluefish (Pomatomus saltatrix) is a highly migratory, sub-tropical, pelagic school species found 28 throughout the world except for the eastern Pacific, and it is the only living species in the family 29 Pomatomidae (Fahay et al. 1999; Lee 2003; Shepherd 2006). Along the U.S. east coast, bluefish 30 commonly occurs in the estuarine and continental shelf waters from Maine to Florida. Bluefish 31 spawn offshore in both spring and summer (Wuenschel et al 2012). Spring-spawned young-of-

32 the-year (YOY) bluefish enter the Middle Atlantic Bight estuaries in late-May to mid-June at 60-

3376 days of age and a mean size of $60 \mathrm{~mm}$ (Able et al. 2003). In contrast, summer-spawned YOY

34 bluefish can remain in the coastal or ocean nursery areas, or they can enter an estuary in mid- to

35 late-August at 33-47 days old and a mean length of $46 \mathrm{~mm}$. Additionally, McBride et al. (1993)

36 reported a relatively less important autumn spawning in northeast Florida.

37 In the nursery estuaries, the bluefish feed voraciously on diverse and usually abundant 38 prey species on which they grow exponentially at rates of $0.9-2.1 \mathrm{~mm} \bullet$ day- 1 to attain sufficient

39 size and condition for successful predator avoidance, emigration in autumn, and overwinter

40 survival (McBride et al. 1993; Juanes et al. 1996; and Able et al. 2003). However, in the course

41 of this rapid growth, in some estuaries, YOY bluefish are potentially exposed to elevated levels

42 of a variety of contaminants. Indeed, Williams (2006) reported that the YOY bluefish take up

43 PCBs as soon as they enter the Hudson River estuary and they continue to bioaccumulate PCBs

44 throughout their nursery residence. Candelmo et al. (2010) reported significant accumulation of

45 PCBs, pesticides, and total mercury in YOY bluefish fed with prey from relatively contaminated

46 Hackensack River compared to prey from relatively clean Tuckerton. The authors reported that

47 bluefish fed with contaminated prey species displayed significantly altered behavior, and resulted

48 in reduced feeding, reduced spontaneous activity, and reduced growth. Delineation of patterns of 
49 habitat utilization in YOY bluefish is thus critically important in understanding the potential for

50 adverse health effects and ultimately the potential for recruitment to the adult stock.

51 Fisheries scientists have employed internal or external physical tags to examine the

52 fidelity and movement of aquatic animals. Able et al. (2003) used internal sequential coded wire

53 microtags to monitor the residency and movements of YOY bluefish in oceanic and estuarine

54 habitats in the New York Bight. Although the bluefish released in the estuary were not captured

55 in the ocean and vice a versa, the authors reported that the poor recapture rates of $0.04-3.4 \%$ of

56 the tagged bluefish made it difficult to discern the patterns of habitat use with this approach.

57 Morton et al. (1993) used external tags to study the movement, growth rates, and fisheries

58 exploitation of YOY bluefish in the Moreton Bay, Queensland, Australia. The authors reported a

59 relatively higher recapture rate of $11 \%$ probably due to the intensive fishery for this species

60 driven by extended residence of YOY bluefish in the sheltered habitats of Moreton Bay. Physical

61 tagging studies can be prohibitively expensive requiring a large number of tagged specimens,

62 albeit with questionable chances of success due to the low and unpredictable tag recapture rates.

63 It is apparent that novel, cost-effective methods are needed to serve as supplement,

64 alternate or replacement to physical tags for monitoring the movements of YOY bluefish within

65 and across the nurseries during their summer residence. Chemical tracers that are naturally

66 embedded in the animals via different trophic, physiological, and biochemical processes offer a

67 potential alternative to the physical tags. As the patterns of tracer chemicals are conceptually

68 integrated over wider spatial and temporal axes, they reflect a true and an integrated image of the

69 long-term life cycles of the test animals. Chou et al. (2002) employed the fingerprints of metal

70 contaminants for modeling lobster migration patterns in the Inner Bay of Fundy. Ashley et al.

71 (2003) used PCB fingerprints to study inter- and intraestuarine differences in American eels and 
72 striped bass from the Hudson and Delaware River estuaries. Rooker et al. (2001) used otolith

73 elemental fingerprints to discriminate northern bluefin tuna from nursery areas in the Pacific

74 Ocean. Takata et al. (2004) used otolith microchemistry to examine YOY bluefish habitat

75 utilization within the Chesapeake Bay and Maryland coastal waters. Dickhut et al. (2009) used

76 select PCB congeners and chlorinated pesticides as tracers of bluefin tuna foraging grounds in

77 the north Atlantic to examine the mixing of Mediterranean and western Atlantic juvenile bluefin

78 tuna within the U.S. mid-Atlantic Bight.

79 The first objective of the present study was to quantify a baseline for PCBs and chlorinated

80 pesticides in YOY bluefish from seven subestuaries of the New York Bight ecosystem. The

81 second objective was to examine the condition indices of YOY bluefish in differently

82 contaminated estuaries, and to understand the role of habitat contaminants such as the PCBs and

83 pesticides in influencing the condition. The third objective was to test the hypothesis that YOY

84 bluefish from different estuaries carry different contaminant fingerprints which can be used as

85 intrinsic marker tags in exploring the habitat utilization and fidelity of YOY bluefish.

\section{Materials and Methods}

\section{Field Collection}

YOY bluefish were collected by using hook-and-line, seine net, or gill net from seven

89 nursery estuaries within the New York Bight (Figure 1), without regard to their spring- or

90 summer-spawning histories, during mid- to late-summer of 1999 to 2004. Specimens were kept

91 on ice in the field, and archived at $-80^{\circ} \mathrm{C}$ in the laboratory. Lengths and weights were measured,

92 and otoliths were removed and archived from individual YOY bluefish for any future age

93 determinations and/or analyses of microconstituents. Sandy Hook Bay specimens collected at

94 two locations in 2000 and 2001 were combined and analyzed as one group. 


\section{Condition Factor}

96 As the YOY bluefish diet has been reported to change with ontogeny (Juanes and Conover 1994;

97 Scharf and Juanes 1996; Gartland et al. 2006), the type of prey item and the caloric content of

98 those items will likely influence the condition and contaminant dynamics differently in the

99 different growth stages of bluefish. Comparisons of condition factors (K) among bluefish

100 specimens from different locations were therefore based on comparisons of similar presumed

101 ages by using length as a proxy for the age. Specimens were divided post collection in two

102 estuary groups based on their length ranges. The first group was comprised of bluefish from

103 Hudson River and Newark Bay with a length range of 133-160 mm. The second group was

104 comprised of Delaware Bay, Great Bay, Great South Bay, and Sandy Hook Bay with a length

105 range of 158-189 mm. Bluefish outside of these length ranges were not considered in the

106 condition comparisons. Navesink River bluefish were not included in the condition comparisons

107 due to the small sample size of 5.

108 Fulton's condition factor, which assumes isometric growth, was calculated by using an

109 expression $\mathrm{K}=1000 \mathrm{~W} / \mathrm{L}^{3}$, in which $\mathrm{W}$ represented the weight of the fish in grams and $\mathrm{L}$

110 represented the length of fish in centimeters (Ricker 1975; Williams 2000).

111 It has been argued that exponent 3 in the Fulton's condition factor equation does not

112 accurately represent the length and weight relationships in a variety of fish species, and that, this

113 method does not permit the comparison of results obtained from individual fish with distinct

114 sizes (Ricker 1975; Bolger and Connolly 1989; Lima et al. 2002). As an alternative, the

115 allometric condition factor (Lima et al. 2002), was calculated from the expression $\mathrm{K}=\mathrm{W} / \mathrm{L}^{\mathrm{b}}$, in

116 which the $\mathrm{b}$ coefficient was estimated from the length-weight relationship equation $\mathrm{W}=\mathrm{aL}^{\mathrm{b}}$ by

117 regressing the natural logarithms of lengths of fish against the natural logarithms of weights. 
118 Values of $b$ coefficient were calculated by using two different regression methods. In the first

119 method, the natural logarithms of lengths of specimens from all estuaries in a given estuary

120 group were regressed against the natural logarithms of weights to give allometric condition

121 factors using one b coefficient. In the second method, the natural logarithms of specimen lengths

122 for each estuary were separately regressed against the natural logarithms of corresponding

123 weights to obtain the allometric condition factors using different $\mathrm{b}$ coefficients for different

124 estuaries. Parallelism of regression lines for a given estuary group was tested by using the

125 ANCOVA homogeneity-of-slopes test.

\section{Analyses of PCBs and Pesticides}

127 Analyses of chlorinated hydrocarbons in YOY bluefish were performed by following the 128 guidelines of Krahn et al. (1988), EPA (1993), Sloan et al. (1993) and Deshpande et al. (2000).

129 Briefly, the individual YOY bluefish specimens were cut into small pieces, freeze-dried, and

130 pulverized using a blender; or minced to small pieces in a blender and then manually dried with

131 sodium sulfate using a mortar and a pestle. Method surrogate internal standards were added to

132 the dried and pulverized homogenates and extracted with methylene chloride in a Soxhlet

133 extraction apparatus. Bulk interfering biological compounds were removed from the target

134 analytes by using florisil/silica/alumina glass column chromatography. Twenty percent of

135 cleaned extract by volume was used for the gravimetric determination of lipids. HPLC surrogate

136 internal standards were added to the extracts and the extracts were further purified on a semi-

137 preparative styrene-divinylbenzene polymer based size-exclusion HPLC column. Solvent of the

138 HPLC fractions containing the target analytes was exchanged from methylene chloride to

139 hexane. GC internal surrogate standards were added to the concentrated extracts and the extracts

140 were analyzed for the select sets of PCB congeners and organochlorine pesticides on a DB-5 
141 fused-silica capillary column by usgin GC-ECD. Measures of quality assurance included

142 analyses of laboratory method blanks, analyses of internal surrogate standards, replicate

143 analyses, analyses of standard reference materials and participation in the international

144 interlaboratory comparison exercises. More details of the analytical protocol are provided in the

145 Supplemental Materials.

146 Method Detection Limit (MDL) Correction

147 For reporting the concentrations, half-MDL values were assigned to the analytes where the

148 measured concentrations were below the MDL values. However, as the MDL value for a

149 particular analyte is a statistically derived number in a separate experiment, its interpretation and

150 its extrapolation to other samples can be subjective, and perhaps erroneous. Since MDL may not

151 accurately represent the true lower detection limit, their replacements with the half-MDL values

152 and adoption in the statistical tests may also result in the truncating of real, low-concentration

153 data points. Therefore, concentrations below MDL values were not adjusted in the statistical tests

154 to allow for the detection of subtle differences between the specimens.

\section{Statistical Analyses}

156 Concentrations of PCB congeners in the individual YOY bluefish were normalized to the

157 concentration of the most prominent and refractory PCB congener, PCB 153 . The \%RSD values

158 were compared for each PCB congener before and after normalization with PCB 153. The

159 magnitude of \% RSD decrease after normalization was then used as a measure of decrease in the

160 intraestuarine data variability and consequent increase in homogeneity of PCB congener

161 fingerprints. The candidates for this test were the concentrations of following major PCB

162 congeners: PCB 153, 138, 187, 180, 118, 149, 183, 95, 66, 49 and 52. Nonparametric Kruskal-

163 Wallis ANOVA on Ranks test was performed to examine statistically significant differences 
164 among concentrations of different contaminants in YOY bluefish from different estuaries

165 (SigmaPlot/SigmaStat 10: Systat Software, Point Richmond, California, USA). Either Dunn's or

166 Holm-Sidak All Pairwise Multiple Comparison Procedure was then used to isolate the YOY

167 bluefish group or groups that differed from the others. Discriminant Function Analysis (DFA)

168 test was performed to examine the possibility of segregating subpopulations of YOY bluefish

169 from different estuaries based on characteristic fingerprints of PCB congeners (Statistica 8.0,

170 Statsoft: Tulsa, Oklahoma, USA). In this test, each PCB congener concentration was normalized

171 to the sum of the concentrations of all detected PCB congeners in an attempt to remove the

172 effects of absolute concentrations on the first principal component (Schwartz and Stalling 1991;

173 Monosson et al. 2003; Wenning et al. 1992).

\section{Results}

\section{Lengths and Weights}

176 Lengths (Figure 2A) and weights (Figure 2B) of YOY bluefish from Hudson River were lowest

177 and these specimens were probably youngest of all bluefish examined. Bluefish from Navesink

178 River, Great Bay, and Delaware Bay appeared to be the oldest specimens, while bluefish from

179 Newark Bay, Great South Bay, and Sandy Hook Bay were intermediate. Length ranges of

180 bluefish selected for comparative analyses within the Hudson River/Newark Bay estuary group

181 (Figure 2C) were not statistically different in t-test as the power of performed test of 0.258 was

182 below the desired power of $0.800(\alpha=0.050)$. Similarly, length ranges of bluefish selected for

183 comparative analyses within the Delaware Bay/Great Bay/Great South Bay/Sandy Hook Bay

184 estuary group (Figure 2D) were not statistically different in one way ANOVA as the power of

185 performed test of 0.119 was below the desired power of $0.800(\alpha=0.050)$. The absence of

186 statistical differences in the selected bluefish ranges in a given estuary group indicated the 
187 possibility of bluefish with similar age ranges in that particular estuary group, and also validated

188 the statistical comparisons of their condition factors. Weight ranges of bluefish within the

189 Hudson River/Newark Bay estuary group (Figure 2E) were statistically different in t-test $(\mathrm{P}=$

190 0.004), with Hudson River bluefish being significantly heavier than Newark Bay bluefish.

191 Weight ranges for the Delaware Bay/Great Bay/Great South Bay/Sandy Hook Bay estuary group

192 (Figure 2F) were significantly different in the Kruskal-Wallis one way ANOVA test $(\mathrm{P}=$

$193<0.001)$. Dunn's all pairwise multiple comparison test suggested that bluefish from Great Bay

194 were significantly heavier than bluefish from Sandy Hook Bay and Great South Bay $(\mathrm{P}<0.05)$.

195 No other statistical differences in bluefish weights were found for this estuary group.

196 Correlations between bluefish lengths and weights were excellent for all YOY bluefish

197 subpopulations (Table 1). P value of 0.5654 was well above 0.05 in the homogeneity-of-slopes

198 test of natural log normalized length-weight regression lines for bluefish from Hudson River and

199 Newark Bay, which suggested the parallelism of regression lines, and parallel but contrasting

200 growth rates in the two most contaminated estuaries. The graphs of natural log normalized

201 length-weight regression lines indicated that for a given length, bluefish from Hudson River were

202 heavier than bluefish from Newark Bay (Figure 3A). A lower p value of 0.0193 for bluefish from

203 Delaware Bay, Great Bay, Great South Bay, and Sandy Hook Bay suggested inequalities of

204 slopes of the respective regression lines, and probably non-parallel and unequal growth rates in

205 the individual estuaries. The regression lines indicated that Great Bay bluefish were heaviest for

206 a given length, and were followed in the approximate decreasing order by bluefish from

207 Delaware Bay, Great South Bay, and Sandy Hook Bay (Figure 3B).

208 Condition Factors 
209 Fulton's condition factor determination method and allometric condition factor determination

210 method that used one b coefficient for all specimens within a given length-range-based estuary

211 group (Lima et al., 2002) gave similar distribution patterns of individual condition factors as well

212 as median condition factors (Figures 4A - 4D). Although these patterns were similar, a lower b

213 coefficient of 2.4506 for the Hudson River/Newark Bay estuary group resulted in relatively high

214 Allometric K values compared to the Fulton K value where exponent 3 was used in the condition

215 factor calculations (Figure 4A and Figure 4B). In contrast, a higher b coefficient of 3.8034 for

216 the Delaware Bay/Great Bay/Great South Bay/Sandy Hook Bay estuary group resulted in

217 relatively low allometric K values compared to the corresponding Fulton K values (Figure 4C

218 and Figure 4D). Patterns of Fulton's condition factors and allometric condition factors calculated

219 as above for a given estuary group appeared to be similar to the respective patterns of bluefish

220 weights. In t-test, the Fulton's condition factors and allometric condition factors using one b

221 coefficient for Hudson River bluefish were significantly greater than respective condition factors

222 for Newark Bay bluefish $(\mathrm{P}=<0.001)$. For the Delaware Bay/Great Bay/Great South Bay/Sandy

223 Hook Bay estuary group, bluefish from Great Bay were generally in better condition and

224 followed by bluefish from Delaware Bay. Bluefish from Great South Bay and Sandy Hook Bay

225 had similar and lowest condition factors in this estuary group. Fulton's condition factors for

226 Great Bay bluefish were significantly greater than the condition factors of bluefish from Sandy

227 Hook Bay and Great South Bay $(\mathrm{P}=<0.05)$. No other significant differences were detected

228 among Fulton's condition factors for this estuary group. Allometric condition factors using one b

229 coefficient were significantly different for the Delaware Bay/Great Bay/Great South Bay/Sandy

230 Hook Bay estuary group in one way ANOVA test $(\mathrm{P}=<0.001)$. Holm-Sidak all pairwise

231 multiple comparison procedure test indicated that allometric condition factors for Great Bay 
232 bluefish were significantly greater than allometric condition factors for bluefish from Great

233 South Bay, Sandy Hook Bay, and Delaware Bay. No other significant differences were detected

234 among condition factors for this estuary group. Given that bluefish length ranges within a given

235 estuary group were approximately similar, it can be argued that fish weights were the major

236 determinants of bluefish condition. Patterns of allometric condition factors based on different $b$

237 values for different estuaries (Figure 4E and Figure 4F) were however inconsistent with the

238 respective weight patterns and therefore these values are not discussed any further.

\section{Lipids-Length and Lipids-Weight Relationships}

240 Lipids were highest in bluefish from Navesink River and Delaware Bay, and followed in

241 decreasing order in bluefish from Great Bay, Sandy Hook Bay, and Newark Bay (Figure 5).

242 Lipids were lowest in bluefish from Hudson River and Great South Bay. Lipids correlated

243 moderately with weights in bluefish from Newark Bay, Navesink River, and Great Bay (Table

244 1), and the correlations were followed in the decreasing order in bluefish from Hudson River,

245 Great South Bay, and Sandy Hook Bay. Lipid-weight correlations were not observed for bluefish

246 from Delaware Bay $(\mathrm{r}=0.03)$. Lipids correlated moderately with lengths in bluefish from

247 Navesink River and Great Bay, and the correlations were followed in the decreasing order in

248 bluefish from Hudson River, Newark Bay, Sandy Hook Bay, and Great South Bay (Table 1).

249 Lengths and lipids were not correlated in bluefish from Delaware Bay.

\section{Lipids-Contaminant Relationships}

251 PCBs correlated moderately well with lipids in the bluefish from Navesink River, Delaware

252 Bay, Sandy Hook Bay, and Great Bay $(\mathrm{R}=0.6521$ to 0.8488$)$, modestly in bluefish from Hudson

253 River, Newark Bay $(\mathrm{R}=0.3865$ to 0.4344$)$, and poorly in bluefish from Great South Bay $(\mathrm{R}=$

254 0.2083) (Table 1). DDTs correlated moderately well with lipids in bluefish from Delaware Bay, 
255 Great Bay, Sandy Hook Bay, and Hudson River $(\mathrm{R}=0.5989$ to 0.8643$)$, modestly in bluefish

256 from Great South Bay and Newark Bay $(\mathrm{R}=0.4082$ to 0.4227$)$, and poorly in bluefish from

257 Navesink River $(\mathrm{R}=0.2474)$ (Table 1$)$. As the contaminants did not correlate with lipids in

258 bluefish from all locations, among-site comparisons using lipid-normalized data were not

259 thought to be of significant relevance, and therefore lipid-normalized data are not discussed

260 further.

261 Size-Contaminant Relationships

262 Concentrations of PCBs and DDTs increased from modestly to moderately with lengths and

263 weights of bluefish from Newark Bay $(\mathrm{R}=0.3413$ to 0.4527$)$, Great Bay $(\mathrm{R}=0.5291$ to 0.6521$)$,

264 and Hudson River $(\mathrm{R}=0.6479$ to 0.8380$)$ (Table 1$)$. These relationships ranged from poor to

265 weak in bluefish from Great South Bay, Sandy Hook Bay, Navesink River, and Delaware Bay (R

$266=-0.8028$ to 0.3362 ). As the size-contaminant relationship was not observed in bluefish from all

267 locations, size covariate was not included in among-site comparisons.

268 Body Weight-Absolute Contaminant Burden Relationships

269 Total body burdens of five major PCB congeners (PCB 153, 138, 187, 180, and 118) and p,p'-

270 DDE in bluefish from Newark Bay and Hudson River increased steadily with body weight;

271 although the slopes of individual regression lines were different (Figure 6A and Figure 6B). The

272 greatest slope, and thus, the greatest uptake rates were observed for p,p'-DDE trend line for

273 Newark Bay bluefish and for PCB 153 trend line for Hudson River bluefish. Despite the

274 differential uptake of different contaminants, the $\mathrm{R}$ values were greater than 0.83 and 0.92 , which

275 suggested good correlations of contaminant body burdens with bluefish weights. A jump in body

276 burden for different analytes was apparent for approximately 24-34 g (142-157 mm long)

277 Newark Bay bluefish and for approximately 25-30 g (126-134 mm long) Hudson River bluefish. 
278 When the YOY bluefish PCB body burden data for all New York Bight subpopulations were

279 pooled, the correlations between YOY bluefish weights and body burdens (Figure 6C) ranged

280 from poor to less than modest with $\mathrm{R}$ values ranging from 0.0245 to 0.1732 .

\section{Body Weight-Contaminant Concentration Relationships}

282 In contrast to body burdens, the concentrations of five major PCB congeners (PCB 153, 138,

283187,180 , and 118) and p,p'-DDE did not appear to increase in similar proportion to the body

284 weights for the Newark Bay bluefish (Figure 6D). Contaminant concentrations-weight

285 correlations for Hudson River bluefish ranged from poor for PCB $180(\mathrm{R}=0.11)$ to moderate for

286 p,p'-DDE $(\mathrm{R}=$ 0.82) (Figure 6E). Slightly negative slope for PCB 180 trend line for Hudson

287 River specimens suggested even a slight decrease in the concentration of PCB 180. When PCB

288 concentration data from all New York Bight YOY bluefish subpopulations were pooled, the

289 correlations between YOY bluefish weights and concentrations (Figure 6F) ranged from poor to

290 modest with $\mathrm{R}$ values ranging from 0.22 to 0.396.

\section{PCBs and Pesticides in YOY Bluefish from Seven Different New York Bight Estuaries}

292 YOY bluefish from Newark Bay generally contained the highest contaminant concentrations

293 regardless of whether the concentration was expressed as a mean value of: (i) individual PCB

294 congener, (ii) PCB homologue series, (iii) sum of all 25 PCB congeners, (iv) Aroclor-equivalent

295 total PCBs, (v) concentrations of two major PCB congeners (PCB 153 and PCB 138), (vi)

296 chlorinated pesticides, or (vii) concentration of a major pesticide, p,p'-DDE (Tables 2 and 3;

297 Figures 7A and 7B). Concentrations in Newark Bay bluefish were followed in the decreasing

298 order by the bluefish from Hudson River, Sandy Hook Bay, Great South Bay, and Navesink

299 River, respectively. Bluefish from Great Bay and Delaware Bay were relatively uncontaminated.

300 Similar results were obtained when the comparisons were made after the PCB data were natural- 
301 logarithm-normalized (Figure 7C). Hexachloro-PCB homologs were generally found in highest

302 concentrations at all locations, and were followed in the generally decreasing order by

303 tetrachloro-PCBs, pentachloro-PCBs, and heptachloro-PCBs (for example: Figure 7D).

304 Kruskul-Wallis One Way ANOVA on Ranks test indicated that differences in the median 305 contaminant concentrations among the YOY bluefish groups were greater than that would be 306 expected by chance, and that there was a statistically significant difference $(\mathrm{P}=<0.001)$. In

307 Dunn's All Pairwise Multiple Comparison Procedure, the difference was considered significant

308 if there was a symbol at the intersection of a horizontal line and a vertical line corresponding to a

309 given pair of estuaries. Thus, the concentrations of PCBs in bluefish from Newark Bay were

310 significantly different from Sandy Hook Bay, Great South Bay, Navesink River, Great Bay, and

311 Delaware Bay (Figure 7E) (Dunn's, $\mathrm{p}<0.05$ ). The concentrations of PCBs in bluefish from

312 Hudson River and Sandy Hook Bay were significantly different from Great Bay and Delaware

313 Bay, and the concentrations of PCBs in bluefish from Great South Bay were significantly

314 different from Delaware Bay (Dunn's, $\mathrm{p}<0.05$ ). The concentrations of $\mathrm{p}, \mathrm{p}$ '-DDE in bluefish from

315 Newark Bay were significantly different from Delaware Bay, Great Bay, Great South Bay, and

316 Sandy Hook Bay (Figure 7F) (Dunn's, p<0.05). The concentrations of p,p'-DDE in bluefish from

317 Hudson River were significantly different from Great South Bay, Delaware Bay, and Great Bay

318 (Dunn's, p<0.05).

\section{Test of Homogeneity of PCB Data}

320 Percent RSD values of concentrations of each of the major PCB congeners were examined as the

321 markers of variability of contaminant exposure in different bluefish within a given estuary.

322 Variability in concentrations estimated from \%RSD values was greatest for bluefish from Sandy

323 Hook Bay and Great South Bay, lower for bluefish from Hudson River and Newark Bay, and 
324 lowest for bluefish from Great Bay (Table 4). PCB congener data were normalized to PCB 153

325 to examine if there were any reductions in the noise in the original PCB data. The $\%$ RSD values

326 of PCB 153 normalized PCB congener data was expected to provide a more realistic

327 representation of patterns of exposure of bluefish to contaminants within a given estuary. While

328 PCB 153 normalization changed \%RSD values very slightly for PCB 52, PCB 49, PCB 95, PCB

329149 and PCB 118 in Great Bay fish, PCB 153 normalization generally decreased intraestuarine

330 variability in the concentrations of other major PCB congeners in Great Bay fish and for major

331 PCB congeners in fish from other estuaries. Net decrease in \% RSD was different for different

332 PCB congeners. It was generally greatest for Sandy Hook Bay fish and lowest for Great Bay fish.

333 Although PCB concentrations were low and similar in Delaware Bay and Great Bay bluefish, the

334 net decrease in \% RSD for Delaware Bay fish was significantly greater than that for Great Bay

335 fish $(\mathrm{P}=<0.001)$.

\section{Discriminant Function Analyses}

337 Prominent PCB congeners in bluefish from Newark Bay in the decreasing concentration order

338 were: PCB 153, 138, 118, 149, 52, 66, 49, 180, 187, 95, and 44 (Table 2, Figure 7D). Prominent

339 PCB congeners in YOY bluefish from Hudson River in the decreasing concentration order were:

340 PCBs 153, 138, 149, 49, 180, 52, 95, 118, 118, 187, 44, 66, and 151 (Table 2, Figure 7D).

341 Despite their qualitative differences, inadequate statistical discrimination between bluefish from

342 Hudson River and Newark Bay in the Dunn's All Pairwise Multiple Comparison Procedure

343 prompted the examination of contaminant data by the Discriminant Function Analysis (DFA)

344 tests.

345 In the DFA tests, the concentrations of individual PCB congeners were normalized to the

346 sum of the concentrations of 25 PCB congeners. Partial Wilk's Lambda for PCB 66 was lowest, 
347 and followed in the increasing order by PCB 95, 194, 126, 187, 105, 206, 49, 138, 209, 118, 44,

$34818,151,52,180,153,128,28,149,195,170$, and 183. Therefore, PCB 66 was considered as the

349 DFA variable that contributed most to discrimination of YOY bluefish subpopulations. DFA

350 Standardized Coefficients for canonical variables test indicated that the first root or the first

351 discriminant function was weighted most heavily by PCB 49, and followed in the decreasing

352 order by PCB 194, 52, 66, 44, 28, 209, 138, 128, 126, 118, 206, 153, and 149. The weightings of

353 PCB 195, 187, 105, 183, 170, 18, 95, and 180 to the first root were comparatively minor. The

354 second root was weighted in the decreasing order by PCB 209, 49, 105, 206, 194, 66, 118, 149 ,

$355187,180,153,28$, and 126. The third root was weighted in the decreasing order by PCB 206,

$356138,118,95,194,52,180,66,126,153,128,151,187,105$, and 149 . The fourth root was

357 weighted in the decreasing order by PCB 138, 187, 209, 153, 180, 118, and 44.

DFA Eigenvalues of the roots indicated that root 1 accounted for $53.2 \%$ of the explained

359 variance, and followed in the decreasing order of $20.2 \%$ for root $2,12.4 \%$ for root $3,9.71 \%$ for

360 root $4,3.38 \%$ for root 5 , and $1.14 \%$ for root 6 . The cumulative proportion of explained variance

361 or the discriminatory power for the first four roots was $95.58 \%$. DFA Means of Canonical

362 Variables test indicated that, for the first root, the canonical mean of -1.39 for Newark Bay

363 bluefish was quite different from canonical mean of -10.09 for Hudson River bluefish, which

364 would allow a clear distinction between the two bluefish subpopulations (Table 5). A clear

365 distinction was noted between bluefish from Hudson River and bluefish from all other locations.

366 The canonical means for the first root also allowed the discrimination between bluefish from

367 Newark Bay and bluefish from Great Bay, Delaware Bay, and Great South Bay (Table 5).

368 Canonical means for the second root allowed similar discrimination between Newark Bay

369 bluefish and Hudson River bluefish (Table 5). The second root provided the separation between 
370 bluefish from Newark Bay and bluefish from Delaware Bay, Hudson River, Great Bay, Great

371 South Bay, and Sandy Hook Bay (Table 5). Canonical means for the third root provided

372 discrimination between Newark Bay bluefish and bluefish from Great South Bay, Navesink

373 River, Sandy Hook Bay, Great Bay and Hudson River (Table 5). Canonical means for the fourth

374 root provided discrimination between Great Bay bluefish, and bluefish from Great South Bay,

375 Navesink River, Delaware Bay, and Newark Bay (Table 5). The fourth root also separated Great

376 South Bay bluefish from bluefish from Sandy Hook Bay and Hudson River (Table 5).

377 The DFA Classification Matrix test indicated that bluefish from Hudson River, Newark

378 Bay, Sandy Hook Bay, Navesink River, and Great Bay were classified to $100 \%$ accuracy to that

379 group. Accuracy of classification was 95.2\% for Great South Bay bluefish, and 93.8\% for

380 Delaware Bay bluefish. A scatterplot of unstandardized canonical scores for Root 2 against Root

3814 showed that the discriminant functions provided a clear discrimination between the most

382 subpopulations of bluefish (Figure 8). Navesink River bluefish appear to be discrete from Sandy

383 Hook Bay bluefish, but this separation is not as clear as that for the other bluefish

384 subpopulations.

385 Discussion

386 Condition Factors

387 Log normalized length-weight regression graphs (Figure 3A) indicated parallel growth 388 curves for bluefish from Hudson River and Newark Bay. However, for any given length, Hudson 389 River bluefish were clearly heavier, and therefore in presumably better condition than Newark 390 Bay bluefish. This result was surprising given the notorious PCB contamination of Hudson River 391 arising from the two General Electric plants, even though the bluefish collection site was located 392 some $260 \mathrm{~km}$ away from the hot-spot source. Despite the relatively small sample size, the 
393 observed differences in the condition reflected clearly contrasting differences in the quality of

394 two habitats. Poor to modest correlations between condition and PCBs in bluefish from Newark

395 Bay $(r=0.1650)$ and Hudson River $(r=0.3205)$ (Table 1) indicated the importance of other abiotic

396 and biotic parameters in the explanation of fish condition. Fisk et al. (2005) reported elevated

397 concentrations of PCBs and pesticides in Candian arctic marine mammals that exceeded the

398 effects thresholds, but except for the polar bears, the authors could not ascertain the evidence of

399 stress in these populations. Other factors reported in the literature that may affect fish condition

400 include dissolved oxygen (Dragun et al. 2013), selenium (Hinck et al. 2007), parasitic

401 infestations (Hinck et al. 2008), and mercury (Hellyerg 2000).

402 Long et al. (1995) reported that Newark Bay sediments were highly toxic to the

403 amphipod Ampelisca abdita compared to the relatively low toxicity of sediments from the lower

404 Hudson River, upper New York Harbor, and portions of lower New York Harbor. The authors

405 reported that sediment toxicity was highly correlated with concentrations of PCBs, dioxins, and

406 pesticides, the concentrations of which often exceeded effects-based guidelines or toxicity

407 thresholds. Litten (2003) and Litten and Fowler (1999) reported that 2,3,7,8-TCDD

408 concentrations in Newark Bay water column were 20-30 times greater than 2,3,7,8-TCDD

409 concentrations in Haverstraw Bay, a location near to where the Hudson River YOY bluefish

410 were collected. Similarly, mercury and cadmium concentrations in Newark Bay water column

411 were 5 and 2 times greater than the concentrations in Haverstraw Bay. It can only be speculated

412 that the synergy of PCBs and pesticides with dioxins, mercury and other less understood stress

413 parameters in Newark Bay affected the quality of key prey species as well as the appetite and

414 predation success of bluefish that resulted in their poor condition. Further assessment of cause-

415 effect relationship is beyond the scope of this article. 


\section{Simulated Growth Rates of YOY Bluefish}

417 Each point on length-weight correlation graphs in Figure 3A and 3B represents length and

418 weight information for different individual YOY bluefish. If it is assumed that different points

419 on this graph for a given estuary represent different developmental stages of one individual

420 hypothetical or a synthetic YOY bluefish, then the length axis can be imagined as age axis and

421 the correlation graph can be viewed as a simulated growth curve. The use of length as an age

422 proxy was based on the studies of McBride et al (1995) and Murt and Juanes (2008-2009).

423 McBride et al (1995) reported approximately linear correlations between age and fork length for

424 bluefish specimens from Narragansett Bay sampled monthly from June-October during 1986-

425 1992. Murt and Juanes (2008-2009) similarly reported approximately linear correlations

426 between age and fork length in YOY and age 1+ bluefish specimens collected in northeast

427 Florida in summer, autumn and winter during 2002 and 2005. Differences in growth rates of

428 YOY bluefish in different estuaries are likely the result of prey quality and predation success,

429 contaminant stress, and other biotic and abiotic factors. Under these assumptions, the simulated

430 growth rates were higher for Hudson River YOY bluefish than the simulated growth rates for

431 Newark Bay bluefish in the Hudson River/Newark Bay bluefish group. For the Delaware

432 Bay/Great Bay/Great South Bay/Sandy Hook Bay group, the simulated growth rates were

433 highest for Great Bay bluefish, and followed in the decreasing order by specimens from

434 Delaware Bay, Great South Bay, and Sandy Hook Bay. Growth rates for Sandy Hook Bay fish

435 and Great South Bay fish were approximately similar. Order of growth rates and condition

436 factors were comparable, which is not very surprising as both indicators are originally based on

437 the length and weight data.

438 Test of Homogeneity of PCB Data 
439 Intraestuarine variations in PCB congener concentrations in YOY bluefish may arise from: (i)

440 subgeographical differences in contaminant concentrations and patterns in the sediments and in

441 prey species, (ii) contributions from undigested prey signatures in YOY bluefish stomach

442 contents which were not purged before the chemical analyses for a variety of reasons ranging

443 from the logistics of handling $-80^{\circ} \mathrm{C}$ frozen specimens to the potential for introducing additional

444 unknown variables, and (iii) alterations in PCB signatures due to different simultaneous

445 physiokinetic processes involving PCB congener uptake, metabolism, and elimination. Certain

446 residual noises in the PCB congener data were expected even after PCB 153 normalization.

447 Assuming that the diet was major route of PCB exposure, Sandy Hook Bay fish appeared to be

448 foraging at differently contaminated trophic levels at the first glance, however PCB 153

449 normalization suggested that overall PCB signatures within Sandy Hook Bay were qualitatively

450 similar (Table 4). In another case, PCB congener concentrations were low in fish from Delaware

451 Bay and Great Bay, and we expected greater noises due to analytical variability in the

452 measurements of low concentrations. We were surprised that the net decreases in \% RSD values

453 for Delaware Bay fish were significantly greater than those for Great Bay fish $(\mathrm{P}=<0.001)$,

454 which suggested that analytical variability is probably less important than the natural variability

455 arising from the biological and habitat factors. Higher natural variability of Delaware Bay

456 bluefish than the variability in Great Bay fish was also evident from \%RSD values before PCB

457153 normalization.

458 Greater \% RSD for Sandy Hook Bay specimens appeared to be in accordance with the

459 collection of specimens over a wider geographical and time range. The results also suggested

460 that contaminant concentrations in sediments in Sandy Hook Bay, and/or prey assemblages were

461 more heterogeneous than the other estuaries. Improved \%RSD values after PCB normalization 
462 also suggested that intraestuarine variability of PCB signatures was qualitatively and similarly

463 low for all estuaries, with a few exceptions. Although PCB concentrations were low and similar

464 in the Delaware Bay and Great Bay bluefish, the Delaware Bay bluefish showed relatively high

465 specimen-to-specimen variability of PCB congener concentrations. The higher variability of

466 PCB congener concentrations in Delaware bluefish suggested greater heterogeneity of

467 sedimentary contaminants and/or prey assemblages in Delaware Bay.

468 PCBs and Pesticides in YOY Bluefish from New York Bight Subestuaries

469 YOY bluefish specimens in the present study were collected from different estuaries in several

470 different years. Williams (2006) reported intra- and interannual differences in PCB congener

471 fingerprints in the Hudson River YOY bluefish, but these fingerprints appeared to be different

472 from PCB congener fingerprints in Newark Bay YOY bluefish analyzed in the present study

473 (data not shown). The comparison of PCB fingerprints in YOY bluefish collected from different

474 estuaries in different years is justified as the spatial trends appear to be more important than the 475 temporal trends.

476 The results of this study reflect the range of chlorinated contaminants to which YOY

477 bluefish were exposed in subestuaries within the New York Bight (Table 2 and Table 3).

478 Concentrations of these chemicals followed the known or anecdotal contamination histories. As

479 expected, Newark Bay and Hudson River bluefish were relatively contaminated, specimens from

480 Sandy Hook Bay, Navesink River, and Great South Bay were moderately contaminated, and

481 those from Great Bay and Delaware Bay were relatively less contaminated. Total Body burdens

482 of PCBs and p,p'-DDE increased with bluefish length and weight, however the concentrations

483 generally increased only poorly to moderately. We hypothesize that bluefish during their nursery

484 residence are in steady-state equilibrium for contaminant uptake. Thus, although they are 
485 continually exposed to incremental contaminants in the estuary, the dilution effects related to the 486 high growth rates qualitatively proportionately compensate for the increase in the body burden, 487 and therefore, the concentrations change only modestly with growth.

488 A jump in the burden of PCBs and p,p'-DDE was apparent when bluefish from Newark 489 Bay and Hudson River reached the size of 138-155 mm and 125-133 mm. This observation may 490 be in part an interesting outcome of the bluefish diet shifts with the changes in ontogeny. Juanes 491 and Conover (1994) reported that YOY bluefish undergo habitat shift from offshore waters to 492 inshore nursery areas at about 40-70 mm length which is accompanied by a diet shift from 493 planktivory to piscivory. The authors reported change in the diets of bluefish after their 494 recruitment to the Great South Bay. Atlantic silverside dominated the diet ( $73 \%$ by weight) when 495 the bluefish were still relatively small $(98 \mathrm{~mm})$. As the bluefish grew to a length of $135 \mathrm{~mm}$ in 496 about 4 weeks, the diet changed to bay anchovy (34\%), shrimp (21\%), and Atlantic silverside 497 (14\%). The authors reported that the mean teleost prey size for the two sampling periods were 498 approximately the same. Scharf and Juanes (1996) reported that YOY bluefish in the Hudson 499 River fed on prey sizes that were smaller than those available in the environment. The authors 500 also reported a general increase in prey size foraging with increased bluefish size across prey 501 species bay anchovy, striped bass, Atlantic silverside, and American shad. Gartland et al (2006) 502 reported ontogenic shifts in YOY bluefish diet in the lower Chesapeake Bay and the coastal 503 ocean of Virginia. Bluefish diet in May was comprised of Atlantic silverside (33.3\%), fish egg 504 (31\%), and crab zoea/megalope (16.6\%). Bluefish diet in June changed to Atlantic silverside 505 (52.1\%), bay anchovy (5.4\%), striped anchovy (3.8\%), white perch (4\%), and opossum shrimp 506 (4.2\%). The diet continued to change as the bluefish grew through November, with steady 507 increases in the composition of bay anchovy and striped anchovy. It is possible in the present 
508 study that YOY bluefish in Hudson River displayed the diet change as they grew to $125-133 \mathrm{~mm}$

509 length. The larger bluefish either foraged on the same species, but more intensively, or they may

510 have started foraging on fattier prey species like bay anchovy and/or menhaden at the same or

511 distant locations. A similar analogy can be applied to the Newark Bay bluefish, except for the

512 fact that these fish had to grow to a little larger size of 138-155 mm length, possibly related to

513 their suboptimal condition due to the apparently compromised habitat parameters in Newark

514 Bay.

\section{Role of Lipids versus Role of Habitat in the Contamination of YOY Bluefish}

516 Lipids are likely to be some of the most important contributors to the fish condition. Being non-

517 polar and lipophilic in nature, it is conceivable that contaminants like PCBs and pesticides will

518 likely bioaccumulate higher in the fattier fish. However, this is probably true only for the

519 comparison of different fish specimens or species from a given general location. We previously

520 reported that lipids in muscle tissues of bluefish from New York Bight were highest,

521 intermediate in black seabass, and tautog, and lowest in summer flounder, and that PCBs, DDTs,

522 and chlordanes in these species followed the lipids trend (Deshpande et al. 2000). We also

523 reported moderate to good correlations between PCBs and lipids for the specimens of a given

524 species (bluefish, $\mathrm{R}=0.7211$; black sea bass, $\mathrm{R}=0.7616$; and tautog, $\mathrm{R}=0.8124$ ). In another

525 study, we reported significantly high concentrations of PCBs in YOY bluefish from different

526 New Bedford Harbor locations (Deshpande et al. 2013) compared to PCB concentrations in

527 YOY bluefish analyzed in the present study. We argue that when one compares fish from

528 different estuaries, the extent of habitat contamination will perhaps play a more important role in

529 the extent of contamination exposure of the fish than the lipid contents alone. It is therefore futile 
530 to compare lipid normalized contaminant data for fish from across different geographical

531 locations with different or sharply contrasting contamination histories.

\section{Grouping of YOY Bluefish Subpopulations}

533 It has been documented that Hudson River receives the majority of its PCB loadings through

534 historical inputs from the two General Electric plants in Hudson Falls and Fort Edward, New

535 York (Brown et al. 1985; Thomann et al. 1991 EPA 2002). In contrast, Monosson et al (2003)

536 indicated that Newark Bay receives its PCB inventory mainly from the diverse local inputs, such

537 as the contaminated rivers, industrial and municipal wastewater discharges, and shipping traffic.

538 The authors reported site-specific differences in PCB profiles in mummichog, with Hudson

539 River fish having greater concentrations of lesser chlorinated congeners relative to more highly

540 chlorinated congeners in Newark Bay fish. Lighter PCB congeners could arise from the lighter

541 Aroclors from the GE contamination of the Hudson River. The heavier PCB congeners in

542 Newark Bay could arise either from point-source of heavier Aroclors in Newark Bay, or the

543 heavier PCB congeners could be associated with the greater proportion of weathered PCBs in

544 Newark Bay. The authors concluded that PCB congener profiles among different mummichog

545 populations likely reflected differences in the congener profiles of the PCB sources to the

546 habitats of those populations, and suggested that PCB congener profiles in organisms can be

547 used to help distinguish PCB sources to aquatic populations. Monosson et al. (2003) provided the

548 first direct evidence that the contaminant patterns in mummichog were different in the Newark

549 Bay and Hudson River mummichog. The present study provides the first direct evidence that the

550 patterns of PCB congeners and chlorinated pesticides are different in Newark Bay and Hudson

551 River bluefish, which also substantiated the Monosson et al. (2003) suggestion that the sources

552 of contamination in these adjacent and relatively contaminated nurseries are different. However, 
553 contrary to the results of Monosson et al (2003) study, the concentrations of lighter PCB

554 congeners in bluefish from Hudson River were not greater than the concentrations of lighter PCB

555 congeners in bluefish from Newark Bay. It remains to be investigated if the diversity and

556 abundance of prey species is also different in the two estuaries. YOY bluefish from the two

557 Sandy Hook Bay locations about $6 \mathrm{~km}$ apart clustered together in the DFA graphs, with some

558 stray specimens, which suggested moderate, within-estuary mixing of fish within Sandy Hook

559 Bay and possibly within other estuaries. Although not quite as clear as some of the other

560 subpopulation groupings, PCB congener patterns in Navesink River bluefish were apparently

561 different than PCB congener patterns in Sandy Hook Bay bluefish (Figure 8). These two

562 collection sites are less than $20 \mathrm{~km}$ apart from each other and the difference in PCB fingerprints

563 may arise from the differences in local sources of PCB fingerprints in the respective habitats as

564 well as limited migrations away from the loosely localized nursery grounds. It was rather

565 remarkable for a field survey to detect such unique differences in PCB fingerprints within a short

566 geographic range. As only five fish from Navesink River were analyzed this difference needs to

567 be substantiated with the analyses of more specimens. The fingerprint technique also

568 distinguished bluefish specimens from various other nurseries suggesting different

569 concentrations and patterns of contaminants in different estuaries.

570 In the present study, we conducted the DFA test for the PCB congener concentrations

571 normalized to the sum of concentrations of 25 PCB congeners. The resulting groupings of some

572 to virtually all subpopulations in DFA graphs suggested the utility of PCB congeners such as

573 PCB 49, 52, 66, 95, 105, 118, 138, 187, 194, 206, 209 as the potentially useful internal tags for

574 studying site fidelity of YOY bluefish in the New York Bight subestuaries. It should be noted

575 that these specific internal tags may be pertinent only in the context of the present data and 
576 perhaps not independently applicable in other studies as the unique contaminant patterns will

577 likely change with the species or the habitat in concern. Increased homogeneity in intraestuarine

578 PCB congener patterns after PCB 153 normalization suggested that bluefish within a given

579 estuary are probably exposed to similar contaminant sources with minor to modest variations.

580 DFA Classification Matrix tests classified bluefish with 100\% accuracy for the Hudson River,

581 Newark Bay, Sandy Hook Bay, Navesink River, and Great Bay. The accuracy of classification

582 was also relatively high for the other bluefish subpopulations with a range of 93.8-95.2\%. As

583 only five specimens were used for the Navesink River bluefish, the DFA resolving power was

584 expected to be limited. Surprisingly, despite the small sample size, the classification accuracy

585 was $100 \%$ for Navesink River bluefish. Although worked out for the Navesink River bluefish, the

586 specimen number of 5 appears to be conceptually insufficient. However, the specimen number of

587 about 20 seemed to be quite sufficient in identifying other different bluefish subpopulations.

588 Inclusion of additional candidate PCB congeners to the variables as well as other compounds to

589 the list may further improve the accuracy of bluefish classification, but that remains to be

590 investigated.

591 Results of PCB and pesticide fingerprint analyses in the present study, results of $\mathrm{Ca} / \mathrm{Sr}$

592 ratios in YOY bluefish otoliths in Takata study (2004), and the tag-recapture studies of Able et

593 al. (2003) and Morton et al. (1993) corroborate the unexpectedly high fidelity of YOY bluefish

594 for extended residences in the respective nursery subestuaries with minimal interestuarine

595 exchange, at least within the New York Bight ecosystem. Given their high-energy reserves and

596 their highly active and migratory trait, YOY bluefish seem to be adequately capable of migrating

597 to other estuaries. But, these movements do not seem to be necessary or bioenergetically

598 profitable as various nursery estuaries already seem to provide plentiful of prey resources to 
599 grow and offer multiple shelters to hide away from the predators. Also, given the school-fish

600 behavior of YOY bluefish, one can speculate that such migrations away from the school network

601 may even not be socially desirable or advantageous.

\section{Conclusions}

603 1. YOY bluefish from Newark Bay generally contained the highest contaminant concentrations,

604 followed in the decreasing order by bluefish from Hudson River, Sandy Hook Bay, Great South

605 Bay, and Navesink River. Bluefish from Great Bay and Delaware Bay were relatively

606 uncontaminated.

607 2. Body burden of $\Sigma$ PCBs and p,p'-DDE increased with the length of YOY bluefish, which

608 suggested incremental exposure during their nursery residence.

609 3. Contaminant concentrations generally increased only poorly to moderately, which suggested

610 steady-state of contaminant uptake resulting from the dilution of contaminants due to the rapid

611 growth of YOY bluefish.

612 4. High condition factors paired with elevated contamination levels in bluefish from Lower

613 Hudson River, as compared with bluefish from Newark Bay with poor condition factors paired

614 with elevated contamination levels, suggested that PCBs and pesticides alone may not determine

615 the condition in these fish.

616 5. Dissimilar patterns of prominent PCB congeners in bluefish from Newark Bay and Lower

617 Hudson River suggested separate contaminant sources in these adjacent subestuaries.

618 6. Normalized PCB congener fingerprints permitted precise statistical discrimination among

619 YOY bluefish specimens from various estuaries, which suggested unexpected fidelity to the

620 nursery estuaries.

621 Management Implications and Future Studies 
As a result of harvest restrictions imposed under Amendment 1 to the Fishery Management

623 Plan (FMP), bluefish are considered rebuilt as of 2009, with stock biomass above the target of

624324 million pounds (MAFMC 2009; ASMFC 2012; NOAA Fishwatch). Shepherd and Nieland

625 (2010) reported that bluefish is currently neither overfished nor it is experiencing overfishing,

626 and that fishing mortality in 2009 was 0.10 , below the biological reference point of 0.19 . The

$6272014 \mathrm{~F}$ estimate of 0.141 also indicates that overfishing is not occurring and that the bluefish

628 stock is not overfished (SAW/SARC- 60, 2015). The NOAA Fishwatch website suggests that

629 although the bluefish stock has been rebuilt, and it is managed sustainably, several key scientific

630 gaps need to be addressed to better inform the management. One of the important scientific gaps,

631 in our opinion, appears to be the dearth of information on the success of contribution of YOY

632 bluefish from differently contaminated nursery habitats to the adult bluefish stock.

633 Subpopulations of YOY bluefish with different health conditions leave the southern New

634 England and Middle Atlantic estuaries in late summer to early fall, and ultimately congregate

635 into a large, southward migrating extensive admix (Shepherd 2006). At this point, it is very

636 difficult to identify the nursery habitat of individual bluefish or predict what percent of the

637 population is competent for migration and overwintering survival from a particular habitat,

638 which complicates efforts in the recovery, conservation, and management of bluefish stock. If we

639 could assign YOY bluefish by using PCBs, pesticides, or other suitable intrinsic tracer tags to the

640 individual estuaries when mixed into the southward migrating population, then the contributions

641 of fish from the individual nursery estuaries to the total bluefish stock could be assessed. From

642 this information, the importance and quality of different habitats in supporting a healthy and

643 sustainable bluefish stock could be determined. Information to this level of detail about critical

644 YOY bluefish habitats does not exist, and it is expected to be useful in the recovery and 
645 management of the decline observed in the bluefish stock (Shepherd 2006). We think that a

646 baseline study using different chemical tracers in YOY bluefish from several nursery grounds in

647 the northeast- and mid-Atlantic would be beneficial. Designation of autumn emigrating mixed

648 population of bluefish to their respective habitats would then help elucidate the habitat-specific

649 recruitment processes, and the effective remediation and management of potentially critical, but

650 currently sub-optimal habitats. It would also be of interest to examine whether lipid mobilization

651 and/or biochemical metabolic processes distort the magnitude of concentrations and/or the

652 integrities of chemical fingerprints in YOY bluefish from various nursery estuaries during their

653 southward migration and overwinter residence in the southern latitudes.

\section{Acknowledgements}

655 The authors sincerely thank Ken Able (Rutgers University), Fred Scharf (University of 656 North Carolina at Wilmington), Josh Stout (Rutgers University), Linda Stehlik (NMFS), Allen 657 Bejda (NMFS), Melissa Newman (NMFS), Dewayne Fox (Rutgers University), Kim McKown 658 (NYDEC), John Rosendale (NMFS), and Shayla Williams (NMFS) for assistance with field 659 collection or chemical analyses.

660 References

Able, K. W., Rowe, P., Burlas, M., and Byrne D. 2003. Use of ocean and estuarine

662 habitats by young of the year bluefish (Pomatomus saltatrix) in the New York Bight. Fish. B. 663 NOAA. 101: 201-214.

664 Ashley, J.T.F., Horwitz, R., Steinbacher, J.C., and Ruppel, B. 2003. A comparison of 665 congeneric PCB patterns in American eels and striped bass from the Hudson and Delaware River 666 estuaries. Mar. Pollut. Bull. 46:1294-1308. 
Bluefish, Pomatomus saltatrix.

669 http://www.asmfc.org/speciesDocuments/bluefish/bluefish_StockStatus.pdf

670 Bolger, T. and Connolly, P. L. 1989. The selection of suitable factors for the

671 measurement and analysis of fish condition. J. Fish Biol., Southampton, v. 34, n. 2, p.171-182.

672 Brown, M.P., Werner, M.B., Sloan, R.J., and Simpson, K.W. 1985. Polychlorinated

673 biphenyls in the Hudson River. Environ. Sci. Technol. 19:656-661.

674 Candelmo, A., Deshpande, A.D., Dockum, B.W., Weis, P., and Weis, J. 2010. The Effect

675 of Contaminated Prey on Feeding, Activity, and Growth of Young-of-the-Year Bluefish,

676 Pomatomus saltatrix, in the Laboratory. Estuaries and Coasts, 33(4):1025-1038.

677 Chou, C.L., Paon, L.A., and Moffatt, J.D. 2002. Metal contaminants for modelling

678 lobster (Homarus americanus) migration patterns in the Inner Bay of Fundy, Atlantic Canada.

679 Mar. Pollut. Bull. 44(2): 134-141.

680

Deshpande, A.D., Draxler, A.F.J., Zdanowicz, V.S., Schrock, M.E., Paulson, A.J.,

682 R.A., May, B. and Rosman, L. 2000. Contaminant levels in muscle of four species of

683 recreational fish from the New York Bight apex. NOAA Tech. Memo. NMFS-NE-157; 99 p.

685 Bioaccumulation of polychlorinated biphenyls and organochlorine pesticides in young-of-the686 year bluefish (Pomatomus saltatrix) in the vicinity of a Superfund Site in New Bedford Harbor, 687 Massachusetts, and in the adjacent waters. Mar. Pollut. Bull.

688 http://dx.doi.org/10.1016/j.marpolbul.2013.04.008 
Dickhut, R.M., Deshpande, A.D., Cincinelli, A., Cochran, M.A., Corsolini, S., Brill,

690 R.W., Secor, D.H., and Graves, J.E. 2009. Atlantic bluefin tuna (Thunnus thynnus) population

691 dynamics delineated by organochlorine tracers. Environ. Sci. Technol. 43:8522-8527.

692 Dragun, Z., Marijić, V.F., Kapetanović, D., Valić, D., Smrzlić, I.V., Krasnići, N., Strižak,

693 Ž., Kurtović, B., Teskeredžić, E., and Raspor, B. 2013. Assessment of general condition of fish

694 inhabiting a moderately contaminated aquatic environment. Environ. Sci. Pollut. Res. 20:4954-

6954968.

EPA. 1993. Laboratory methods manual estuaries. EPA Doc. 600/4-91/024; 289 p.

697 Available from: EPA Office of Research and Development, Cincinnati, OH.

699 Environmental Protection Agency, New York, EPA/ROD/R02-02/013. Also available on the

700 web as: <http:/www.epa.gov/superfund/sites/rods/fulltext/r0202013.pdf>.

Fahay, M.P., Berrien, P.L., Johnson, D.L., and Morse, W.M. 1999. Bluefish, Pomatomus

702 saltatrix, life history and habitat characteristics. NOAA Tech. Memo. NMFSNE-144.

703 Fisk, A.T., De Wit, C.A., Wayland, M., Kuzyk, Z. Z., Burgess, N., Letcher, R., Braune,

704 B., Norstrom, R., Blum, S. P., Sandau, C., Lie, E., Larsen, H., Joergen, S., Skaare, J. U., and

705 Muir, D. C.G. 2005. An assessment of the toxicological significance of anthropogenic

706 contaminants in Canadian arctic wildlife. Sci. Total Environ. 351-352: 57-93.

707 Gartland, J., Latour, R.J., Halvorson, A.D., and Austin, H.M. 2006. Diet Composition of

708 Young-of-the-Year Bluefish in the Lower Chesapeake Bay and the Coastal Ocean of Virginia.

709 Trans. Am. Fish. Soc. 135:371-378. 

MA. http://www.epa.gov/region1/lab/reportsdocuments/ctriverftr2000/chapter5.pdf Anderson, P.J., Coyle, J.J., and Tillitt, D.E. 2007. Chemical contaminants, health indicators,

715 and reproductive biomarker responses in fish from the Colorado River and its tributaries. Sci. 716 Total Environ. 378(3):376-402.

Hinck, J.E., Blazer, V.S., Denslow, N.D., Echols, K.R., Gale, R.W., Wieser, C., May,

718 T.W., Ellersieck, M., Coyle, J.J., and Tillitt, D.E. 2008. Chemical contaminants, health

719 indicators, and reproductive biomarker responses in fish from rivers in the southeastern United

720 States. Sci. Total Environ. 390:538-557.

Juanes, F. and Conover, D.O. 1994. Rapid growth, high feeding rates, and early piscivory

722 in young-of-the-year bluefish (Pomatomus saltatrix). Can. J. Fish. Aquat. Sci. 51:1752-1761.

724 of Pomatomus saltatrix: a global approach. Mar. Freshwater Res. 47: 365-79.

725 Krahn, M.M., Wigren, C.A., Pearce, R.W., Moore, L.K., Bogar, R.G., MacLeod, W.D.

726 Jr., Chan, S.-L., and Brown, D.W. 1988. Standard analytical procedures of the NOAA National

727 Analytical Facility, 1988: new HPLC cleanup and revised extraction procedures for organic

728 contaminants. NOAA Tech. Memo. NMFS FNWC-153; 52 p.

Lee, L. 2003. Population assessment and short-term stock projections of the U.S. east

730 coast bluefish, Pomatomus saltatrix, stock. A report to the Atlantic States Marine Fisheries

731 Commission and Mid-Atlantic Fishery Management Council Monitoring Committee.

732 http://www.asmfc.org/speciesDocuments/bluefish/annualreports/bluefishstockassess03.pdf 
Lima S.E., Jr., Cardone, I. B., and Goitein, R. 2002. Determination of a method for

734 calculation of Allometric Condition Factor of fish. Acta Sci. 24(2):397-400.

Litten, S. and Fowler, B. 1999. Contaminant Assessment and Reduction Project (CARP).

736 Toxic chemicals in New York Harbor and vicinity - sources and ambient concentrations of

737 dioxins and PCBs from large volume water column sampling. In Abstract Book of the 20th

738 Annual Meeting of the Society of Environmental Toxicology and Chemistry, Philadelphia,

739 Penn., 14-18 November 1999. http://www.dec.ny.gov/docs/water_pdf/organicposter.pdf

740 Litten, S. 2003. Contaminant Assessment and Reduction Project Water. CARP Final

741 Report. Bureau of Water Assessment and Management Division of Water New York State

742 Department of Environmental Conservation. August 2003. 158 pp.

743 http://www.dec.ny.gov/docs/water_pdf/carp.pdf

744 Lloret, J., de Sola, L.G., Souplet, A., and Galzin, R. 2002. Effects of large-scale habitat

745 variability on condition of demersal exploited fish in the north-western Mediterranean. ICES J.

746 Mar. Sci. 59 (6):1215-1227.

747 Long E.R., Wolfe, D.A., Scott, K.J., Thursby, G.B., Stern, E.A., Peven, C., and Schwartz,

748 T. 1995. Magnitude and Extent of Sediment Toxicity in the Hudson-Raritan Estuary. NOAA

749 Tech. Memo. NOS ORCA 88. National Status and Trends Program for Marine Environmental

750 Quality. Silver Spring, Maryland. August 1995.

MAFMC. 2009. Bluefish Stock Declared Rebuilt.

752 http://www.mafmc.org/newsfeed/bluefish-stock-declared-rebuilt

753 McBride, R.S., Ross, J. L., and Conover, D.O. 1993. Recruitment of bluefish Pomatomus

754 saltatrix to estuaries of the U.S. South Atlantic Bight. Fish. B. - NOAA. 91: 389-395. 
McBride, R.S., Scherer, M.D., and Powell, J.C. 1995. Correlated variations in abundance,

756 size, growth, and loss rates of age-0 bluefish in a southern New England Estuary. Trans. Am.

757 Fish. Soc. 124(6):898-910.

Monosson, E., Ashley, J.T.F., McElroy, A.E., Woltering, D., and Elskus A.A. 2003. PCB

congener distributions in muscle, liver and gonad of Fundulus heteroclitus from the lower

760 Hudson River Estuary and Newark Bay. Chemosphere 52: 777-787.

761

Morton, R. M., Halliday, I., and Cameron, D. 1993. Movement of tagged juvenile Tailor

762 (Pomatomus saltatrix) in Moreton Bay, Queensland. Aust. J. Mar. Fresh. Res. 44:811-816.

Murt, J. and Juanes, F. 2008-2009. Cohort-specific winter growth rates of YOY Bluefish,

764 Pomatomus saltatrix, in Northeast Florida Estuaries: Implications for Recruitment. J. Northw.

765 Atl. Fish. Sci. 41:221-231.

766

NOAA FishWatch. U.S. Seafood Facts. Bluefish.

767 http://www.fishwatch.gov/seafood_profiles/species/bluefish/species_pages/bluefish.htm

768 Ricker, W. E. 1975.Computation and interpretation of the biological statistics of fish

769 populations. Bull. Fish. Res. Bd. Can., Ottawa, v. 191, p.1-382.

770 Rooker, J.R., Secor, D.H., Zdanowicz, V.S. and Itoh, T. 2001. Discrimination of northern

771 bluefin tuna from nursery areas in the Pacific Ocean using otolith elemental fingerprints. Mar.

772 Ecol. Progr. Ser. 218: 275-282.

773

SAW/SARC- 60. 2015. Stock Assessment of Bluefish for 2015. SAW/SARC- 60.

774 Bluefish Assessment Report. Working Paper B1. May 18, 2015.

775 Scharf, F.S. and Juanes, F. 1996. Estimating piscine prey size from partial remains:

776 testing for shifts in foraging mode by bluefish in the Hudson River. Section IV: 37 pp. In: J.R.

777 Waldman, W.C. Nieder, and E.A. Blair (Eds.). Final Reports of the Tibor T. Polgar Fellowship 
778 Program, 1995. Hudson River Foundation, New York.

779 http://www.hudsonriver.org/ls/reports/Polgar_Scharf_TP_04_95_final.pdf

780 Schwartz, T.R. and Stalling, D.L. 1991. Chemometric comparison of polychlorinated

781 biphenyl residues and toxicologically active polychlorinated biphenyl congeners in the eggs of

782 Forster's terns (Sterna fosteri). Arch. Environ. Contam. Toxicol. 20: 183-199.

783 Shepherd, G. 2006. Status of Fishery Resources off the Northeastern US. Bluefish

784 (Pomatomus saltatrix). NEFSC - Resource Evaluation and Assessment Division. Revised

785 December 2006. 10 pp.

786 http://www.nefsc.noaa.gov/sos/spsyn/op/bluefish/archives/25_Bluefish_2006.pdf

787 Shepherd, G.R. and Nieland, J. 2010. Bluefish 2010 Stock Assessment Update. Northeast

788 Fisheries Science Center Reference Document 10-15. July 2010. 33 pp.

789 http://www.nefsc.noaa.gov/publications/crd/crd1015/crd1015.pdf

Sloan, C.A., Adams, N.G., Pearce, R.W., Brown, D.W., and Chan, S.-L. 1993. Northwest

791 Fisheries Science Center organic analytical procedures. In: Lauenstein, G.G.; Cantillo, A.Y., eds.

792 Sampling and analytical methods of the National Status and Trends Program, National Benthic

793 Surveillance and Mussel Watch Projects, 1984-1992. Vol. 4. Comprehensive descriptions of

794 trace organic analytical methods. NOAA Tech. Memo. NOS ORCA 71; pp. 53-97.

795 Takata, L.T. 2004. Habitat use and cohort recruitment dynamics of juvenile bluefish,

796 Pomatomus saltatrix, in diverse Maryland nursery systems. M.S. Thesis. University of

797 Maryland. 110 pp.

798 Thomann, R.V., Mueller, J.A., Winfield, R.P., and Huang, C. 1991. Model of fate and

799 accumulation of PCB homologues in the Hudson Estuary. J. Environ. Eng. 117:161-178. 
801 Chemometric comparisons of polychlorinated dibenzo-p-dioxin and dibenzofuran residues in

802 surficial sediments from Newark Bay, New Jersey and other industrialized waterways. Arch.

803 Environ. Contam. Toxicol. 22:397-413.

804 Williams, J. E. 2000. The Coefficient of Condition of Fish. Chapter 13 In: Schneider,

805 James C. (ed.) 2000. Manual of fisheries survey methods II: with periodic updates. Michigan

806 Department of Natural Resources, Fisheries Special Report 25, Ann Arbor.

807 http://www.dnr.state.mi.us/publications/pdfs/IFR/manual/SMII\%20Chapter13.pdf

808 Williams, S.D. 2006. Bioaccumulation patterns of organochlorines in young-of-the-year

809 bluefish (Pomatomus saltatrix) in the Hudson River Estuary. Ph.D. Dissertation. Florida

810 Agricultural and Mechanical University, Tallahassee, Florida.

811 Wuenschel, M.J., Able, K.W., Buckel, J.A., Morley, J.W., Lankford, T., Branson, A.C.,

812 Conover, D.O., Drisco, D., Jordaan, A., Dunton, K., Secor, D.H., Woodland, R.J., Juanes, F., and

813 Stormer, D. 2012. Recruitment Patterns and Habitat Use of Young-of-the-Year Bluefish along

814 the United States East Coast: Insights from Coordinated Coastwide Sampling. Rev. Fish. Sci.

$81520(2): 80-102$.

816

817 


\section{Figures}

819 Figure 1. Locations of YOY bluefish collections in the New York Bight estuaries.

820 Figure 2A. A box and whisker summary graph of lengths of YOY bluefish sampled from

821 different New York Bight estuaries. Values that are "far" from the middle of the distribution are

822 referred to as outliers and extreme values. Outlier values are those which are outside of the 1.5

823 box length range from the upper and lower values of the box. Extreme values are those which are

824 outside of the 3 box length range from the upper and lower values of the box.

825 Figure 2B. A box and whisker summary graph of weights of YOY bluefish sampled from

826 different New York Bight estuaries. Values that are "far" from the middle of the distribution are

827 referred to as outliers and extreme values. Outlier values are those which are outside of the 1.5

828 box length range from the upper and lower values of the box. Extreme values are those which are

829 outside of the 3 box length range from the upper and lower values of the box.

830 Figure 2C. A box and whisker summary graph of Fulton's condition factors for YOY bluefish

831 sampled from Hudson River and Newark Bay. Values that are "far" from the middle of the

832 distribution are referred to as outliers and extreme values. Outlier values are those which are

833 outside of the 1.5 box length range from the upper and lower values of the box. Extreme values

834 are those which are outside of the 3 box length range from the upper and lower values of the box.

835 Figure 2D. A box and whisker summary graph of Fulton's condition factors for YOY bluefish

836 sampled from Delaware Bay, Great Bay, Great South Bay, and Sandy Hook Bay. Values that are

837 "far" from the middle of the distribution are referred to as outliers and extreme values. Outlier

838 values are those which are outside of the 1.5 box length range from the upper and lower values

839 of the box. Extreme values are those which are outside of the 3 box length range from the upper

840 and lower values of the box. 
841 Figure 2E. A box and whisker summary graph of weights of YOY bluefish sampled from

842 Hudson River and Newark Bay. Values that are "far" from the middle of the distribution are

843 referred to as outliers and extreme values. Outlier values are those which are outside of the 1.5

844 box length range from the upper and lower values of the box. Extreme values are those which are 845 outside of the 3 box length range from the upper and lower values of the box.

846 Figure 2F. A box and whisker summary graph of weights of YOY bluefish sampled from

847 Delaware Bay, Great Bay, Great South Bay, and Sandy Hook Bay. Values that are "far" from the 848 middle of the distribution are referred to as outliers and extreme values. Outlier values are those

849 which are outside of the 1.5 box length range from the upper and lower values of the box.

850 Extreme values are those which are outside of the 3 box length range from the upper and lower 851 values of the box.

852 Figure 3A. Natural log-normalized length-weight relationship for YOY bluefish from Hudson

853 River and Newark Bay.

854 Figure 3B. Natural log-normalized length-weight relationship for YOY bluefish from Delaware 855 Bay, Great Bay, Great South Bay, and Sandy Hook Bay.

856 Figure 4A. A box and whisker summary graph of Fulton's condition factors for YOY bluefish 857 sampled from Hudson River and Newark Bay. Values that are "far" from the middle of the 858 distribution are referred to as outliers and extreme values. Outlier values are those which are 859 outside of the 1.5 box length range from the upper and lower values of the box. Extreme values 860 are those which are outside of the 3 box length range from the upper and lower values of the box. 861 Figure 4B. A box and whisker summary graph of allometric condition factors for YOY bluefish 862 sampled from Hudson River and Newark Bay by using the same "b" value for both estuaries. 863 Values that are "far" from the middle of the distribution are referred to as outliers and extreme 
864 values. Outlier values are those which are outside of the 1.5 box length range from the upper and

865 lower values of the box. Extreme values are those which are outside of the 3 box length range

866 from the upper and lower values of the box.

867 Figure 4C. A box and whisker summary graph of Fulton's condition factors for YOY bluefish

868 sampled from Delaware Bay, Great Bay, Great South Bay, and Sandy Hook Bay. Values that are

869 "far" from the middle of the distribution are referred to as outliers and extreme values. Outlier

870 values are those which are outside of the 1.5 box length range from the upper and lower values

871 of the box. Extreme values are those which are outside of the 3 box length range from the upper

872 and lower values of the box.

873 Figure 4D. A box and whisker summary graph of allometric condition factors for YOY bluefish

874 sampled from Delaware Bay, Great Bay, Great South Bay, and Sandy Hook Bay by using the

875 same "b" value for all estuaries. Values that are "far" from the middle of the distribution are

876 referred to as outliers and extreme values. Outlier values are those which are outside of the 1.5

877 box length range from the upper and lower values of the box. Extreme values are those which are

878 outside of the 3 box length range from the upper and lower values of the box.

879 Figure 4E. A box and whisker summary graph of allometric condition factors for YOY bluefish

880 sampled from Hudson River and Newark Bay by using different "b" values for different

881 estuaries.

882 Figure 4F. A box and whisker summary graph of allometric condition factors for YOY bluefish

883 sampled from Delaware Bay, Great Bay, Great South Bay, and Sandy Hook Bay by using

884 different "b" values for different estuaries. Values that are "far" from the middle of the

885 distribution are referred to as outliers and extreme values. Outlier values are those which are 
886 outside of the 1.5 box length range from the upper and lower values of the box. Extreme values 887 are those which are outside of the 3 box length range from the upper and lower values of the box. 888 Figure 5. A box and whisker summary graph of \% lipids in YOY bluefish sampled from different 889 New York Bight estuaries.Values that are "far" from the middle of the distribution are referred to 890 as outliers and extreme values. Outlier values are those which are outside of the 1.5 box length 891 range from the upper and lower values of the box. Extreme values are those which are outside of 892 the 3 box length range from the upper and lower values of the box.

893 Figure 6A. Absolute body burden - body weight relationships for 5 major PCB congeners and 894 p,p'-DDE in Newark Bay YOY bluefish.

895 Figure 6B. Absolute body burden - body weight relationships for 5 major PCB congeners and 896 p,p'-DDE in Hudson River YOY bluefish.

897 Figure 6C. Absolute body burden - body weight relationships for 5 major PCB congeners and 898 p,p'-DDE in all YOY bluefish.

899 Figure 6D. Concentration - body weight relationships for 5 major PCB congeners and p,p'-DDE 900 in the Newark Bay YOY bluefish.

901 Figure 6E. Concentration - body weight relationships for 5 major PCB congeners and p,p'-DDE 902 in the Hudson River YOY bluefish.

903 Figure 6F. Concentration - body weight relationships for 5 Major PCB congeners and p,p'-DDE 904 in all YOY bluefish.

905 Figure 7A. A box and whisker summary graph of Aroclor equivalent PCB concentrations in 906 YOY bluefish sampled from different New York Bight estuaries. Values that are "far" from the 907 middle of the distribution are referred to as outliers and extreme values. Outlier values are those 908 which are outside of the 1.5 box length range from the upper and lower values of the box. 
909 Extreme values are those which are outside of the 3 box length range from the upper and lower

910 values of the box.

911 Figure 7B. A box and whisker summary graph of p,p'-DDE concentrations in YOY bluefish

912 sampled from different New York Bight estuaries. Values that are "far" from the middle of the

913 distribution are referred to as outliers and extreme values. Outlier values are those which are

914 outside of the 1.5 box length range from the upper and lower values of the box. Extreme values

915 are those which are outside of the 3 box length range from the upper and lower values of the box.

916 Figure 7C. A box and whisker summary graph of natural log-normalized Aroclor equivalent PCB

917 concentrations in YOY bluefish sampled from different New York Bight estuaries. Values that

918 are "far" from the middle of the distribution are referred to as outliers and extreme values.

919 Outlier values are those which are outside of the 1.5 box length range from the upper and lower

920 values of the box. Extreme values are those which are outside of the 3 box length range from the

921 upper and lower values of the box.

922 Figure 7D. Non-normalized concentrations of PCB congeners in terms of homologs in YOY

923 bluefish from Newark Bay and Hudson River.

924 Figure 7E. Significant differences in Aroclor equivalent PCB concentrations in YOY bluefish

925 from New York Bight estuaries. The difference is significant if there a symbol at the intersection

926 of a horizontal line and a vertical line corresponding to a given pair of estuaries.

927 Figure 7F. Significant differences in p,p'-DDE concentrations in YOY bluefish from New York

928 Bight estuaries. The difference is significant if there a symbol at the intersection of a horizontal

929 line and a vertical line corresponding to a given pair of estuaries. 
930 Figure 8. Groupings of YOY bluefish from different New York Bight estuaries based on

931 discriminant function analyses of fingerprints of individual PCB congener concentrations

932 normalized to the sum of the concentrations of 25 PCB congeners.

933 
934 Tables

935 Table 1. Pearson product moment correlation coefficients (R) for correlations between different

936 physical and chemical parameters measured in YOY bluefish from different estuaries in the New

937 York Bight.

938 Table 2. MDL corrected minimum, maximum, median, and average concentrations of individual

939 PCB congeners, total PCBs, and Aroclor estimates in YOY bluefish in New York Bight

940 estuaries; ng•g-1 wet weight.

941 Table 3. MDL corrected minimum, maximum, median, and average concentrations of individual

942 pesticides in YOY bluefish in New York Bight estuaries; ng•g-1 wet weight.

943 Table 4. Examination of decrease in \%RSD of concentrations of PCB congeners after PCB 153

944 normalization.

945 Table 5. Dicriminant function analysis (DFA): means of canonical variables test for PCB

946 congeners in bluefish normalized to the sum of 25 PCB congeners. 
Figure 1

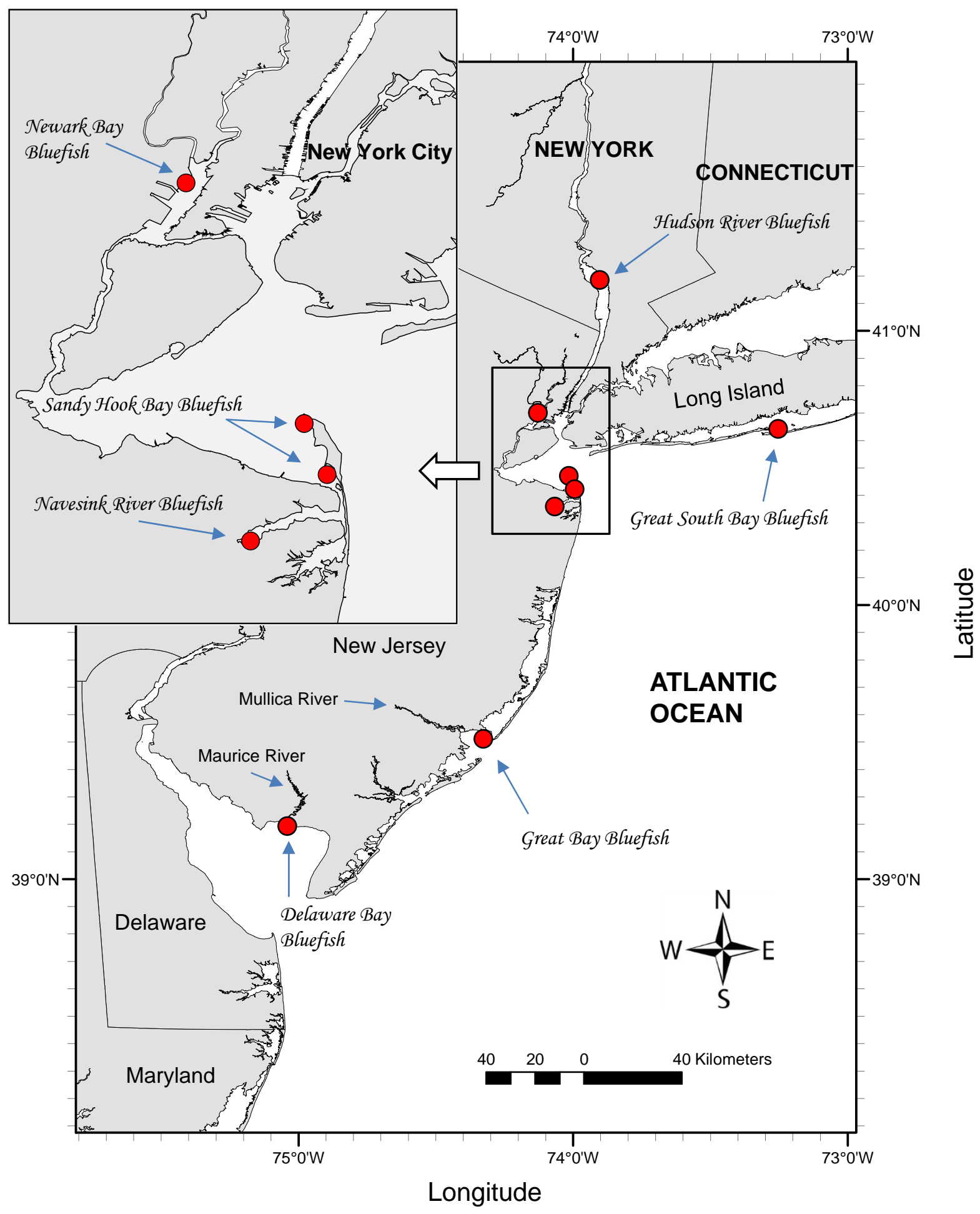


Figure 2A

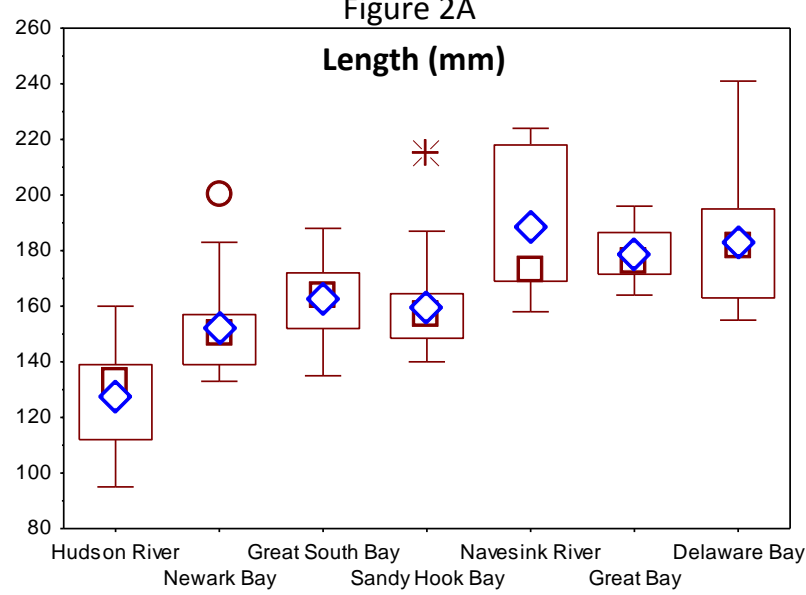

Figure 2C

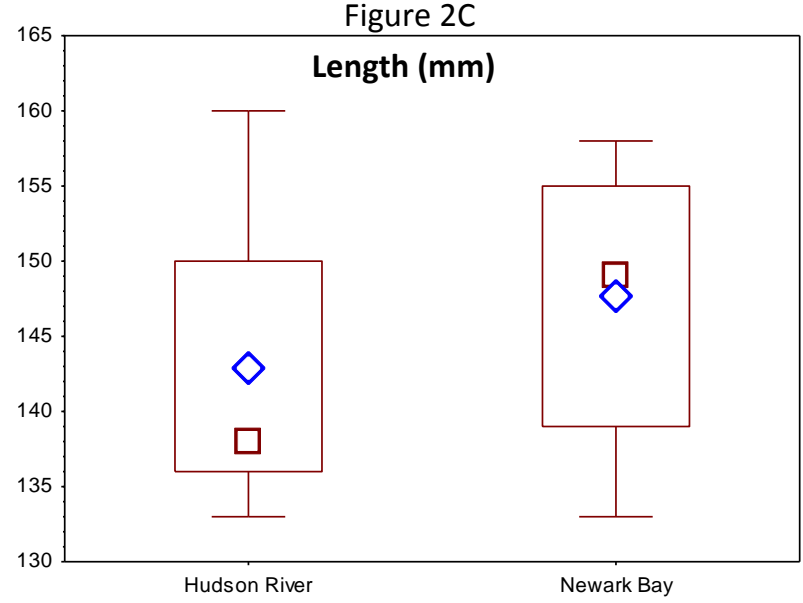

Figure 2E

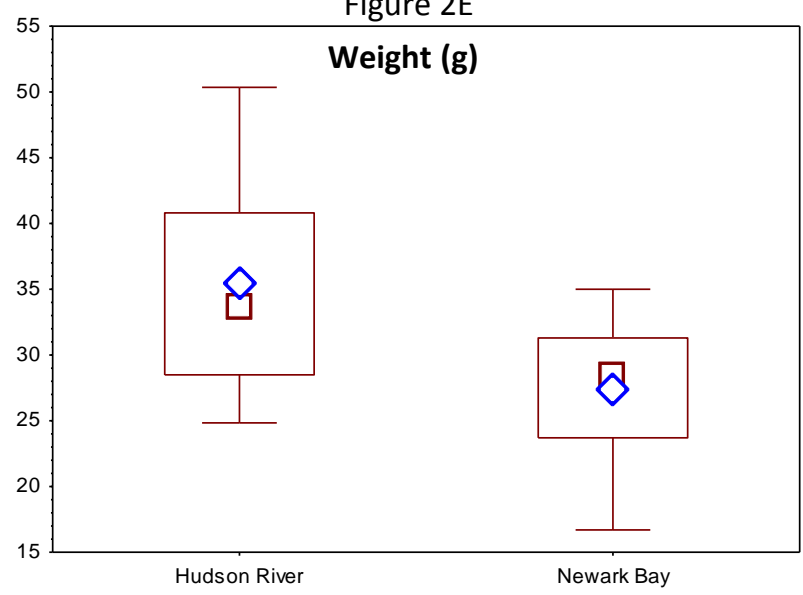

Figure 2B

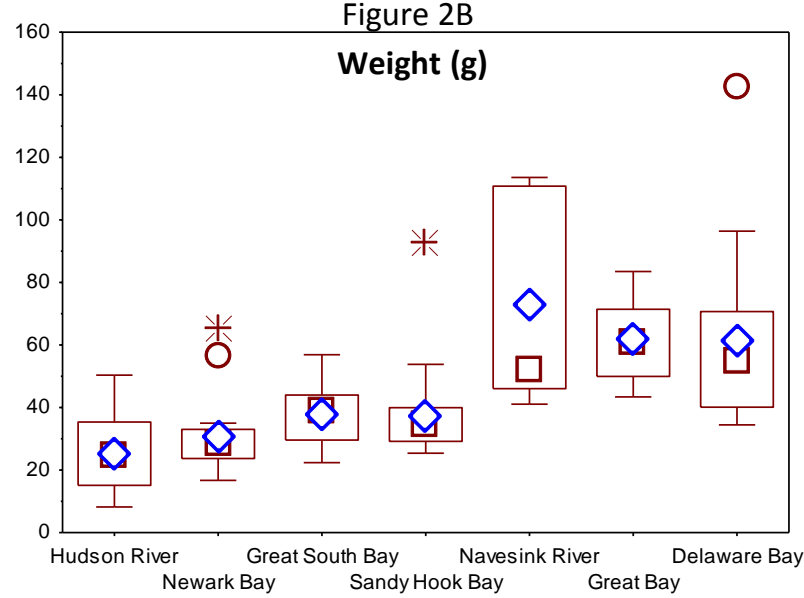

Figure 2D

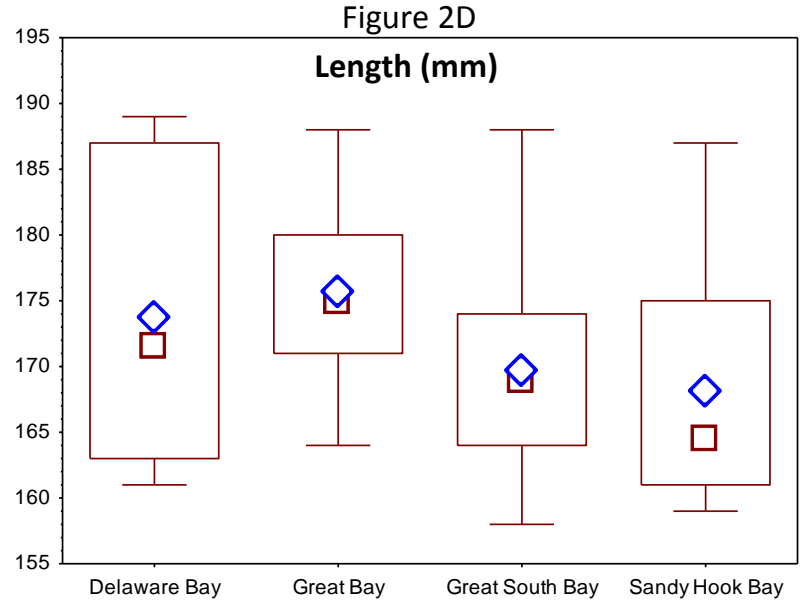

Figure 2F

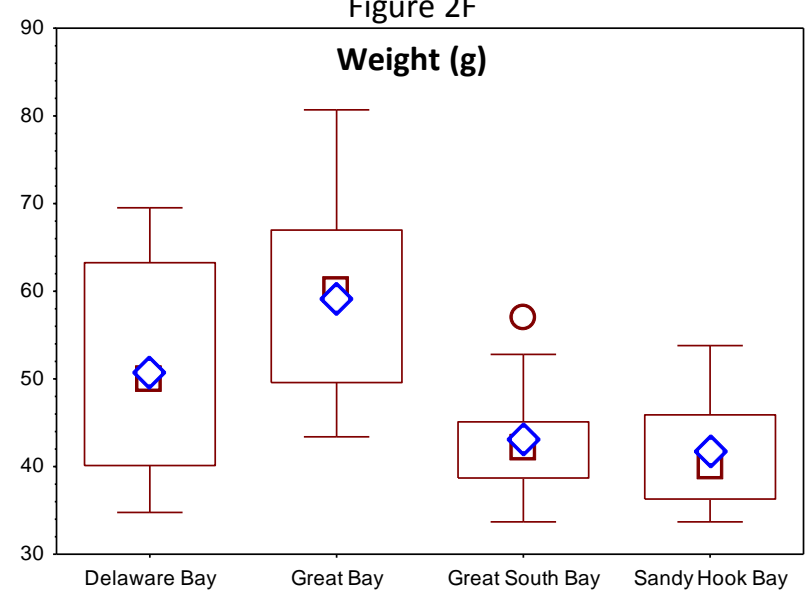

Median $\square 25 \%-75 \%$ I Non-Outlier Range O Outliers * Extremes $\diamond$ Mean 
Figure $3 \mathrm{~A}$

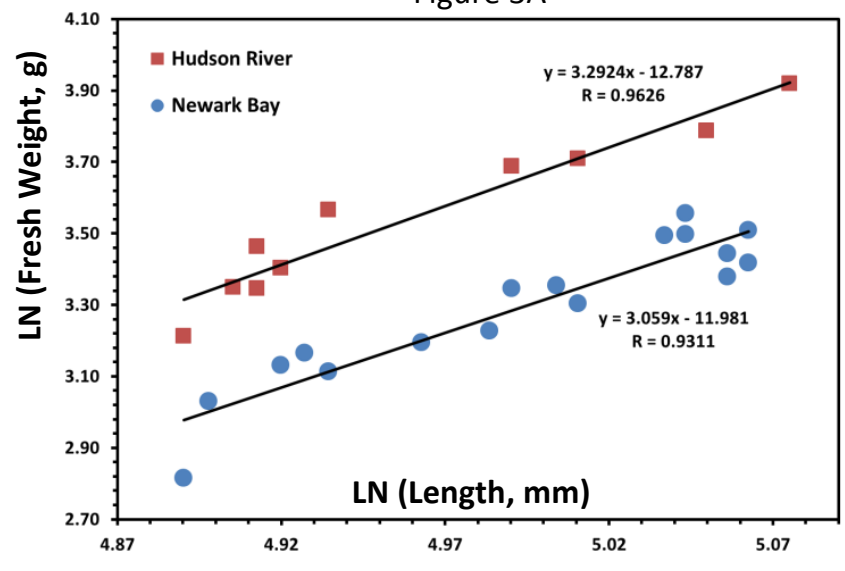

Figure 3B

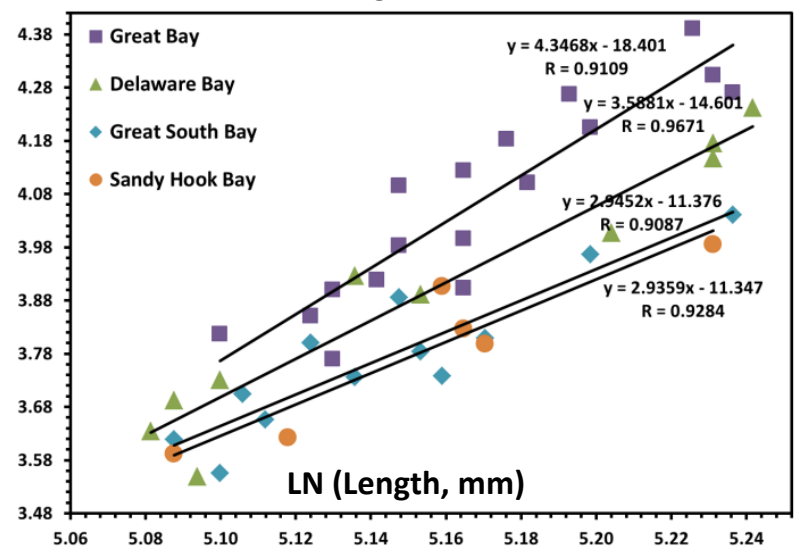



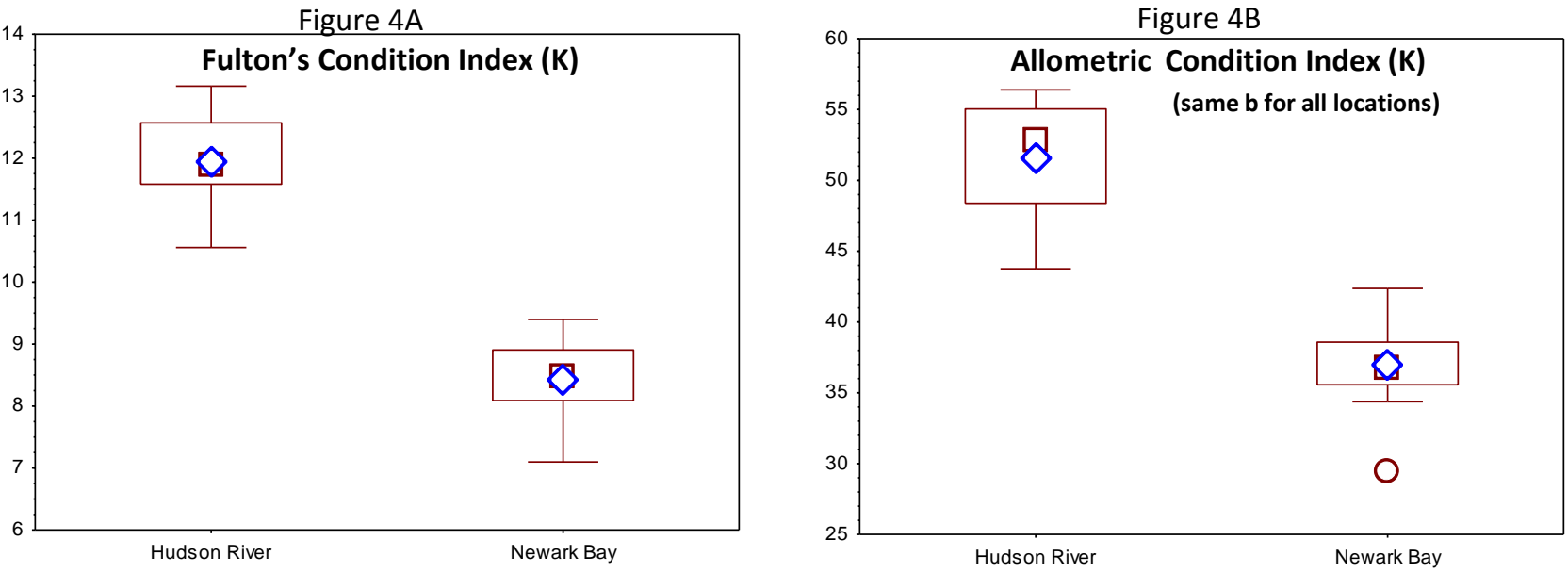

Figure 4C

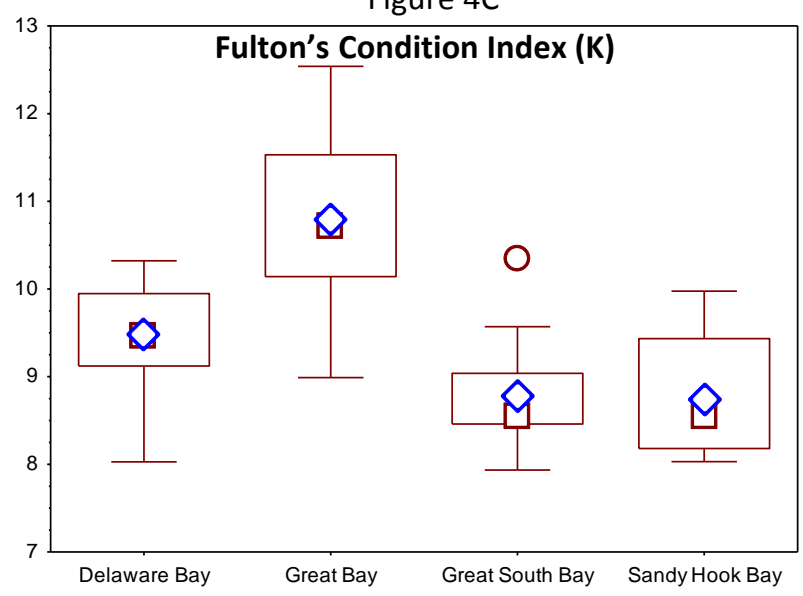

Figure 4D

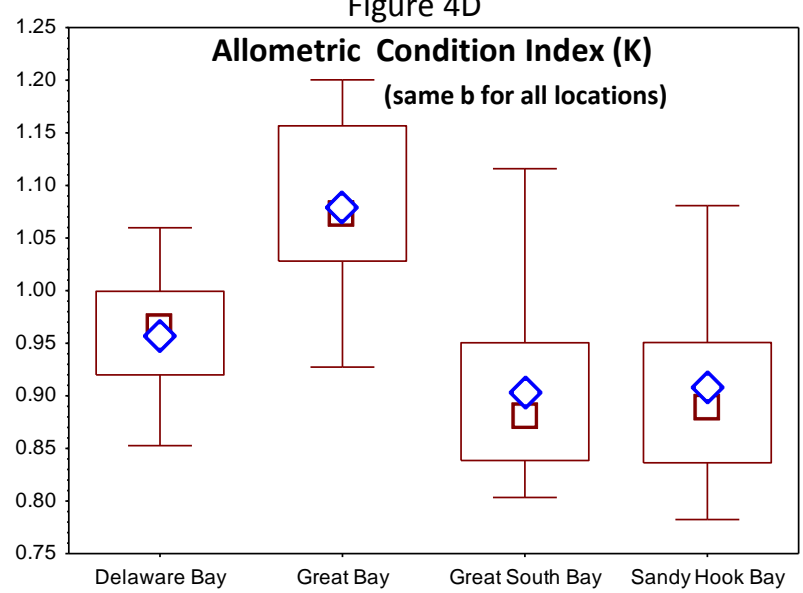

Figure 4E

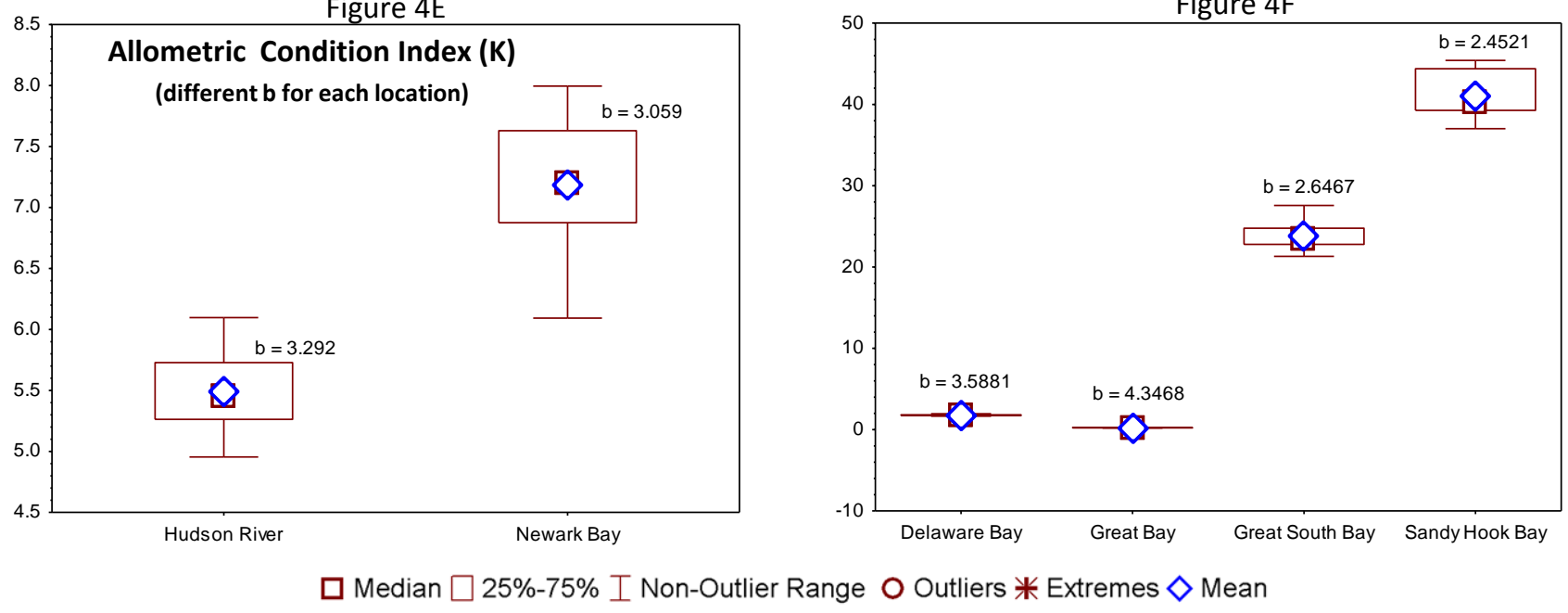


Figure 5

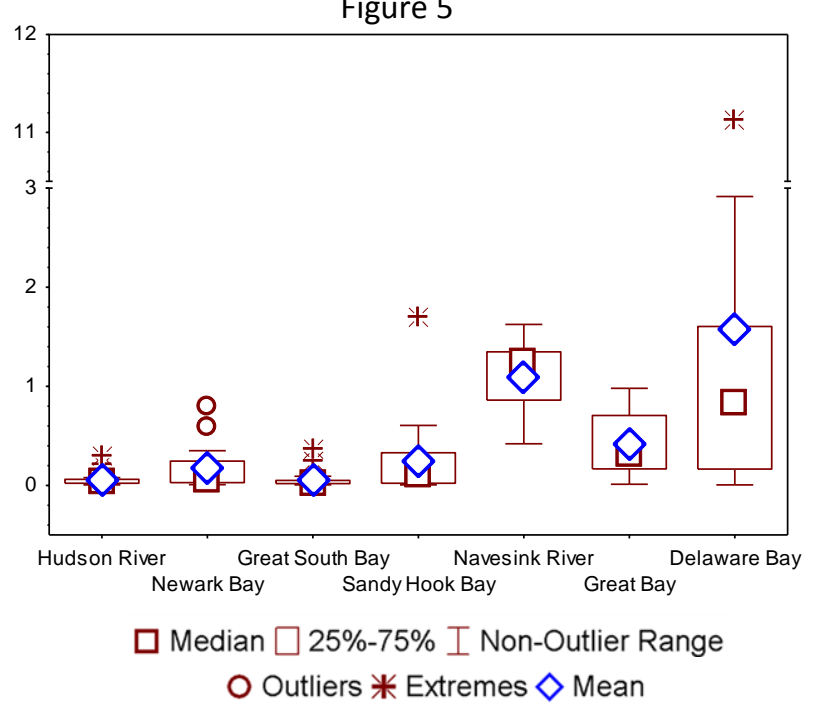

https://mc06.manuscriptcentral.com/cjfas-pubs 
Absolute Body Burden of PCB

Congeners and DDTs (pg)
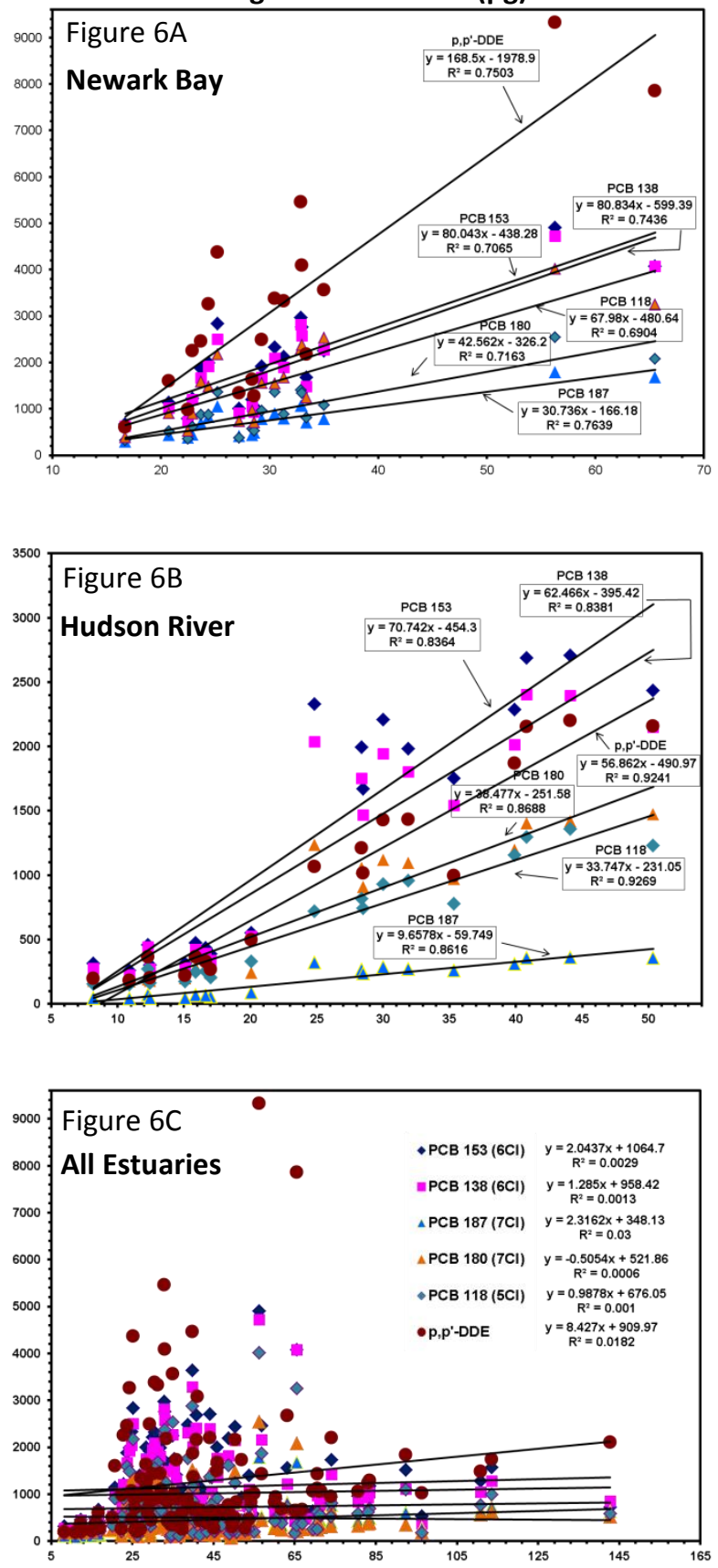

Fresh Weight of YOY Bluefish (g)
Concentration of PCB Congeners and DDTs (ng/g, wet weight)
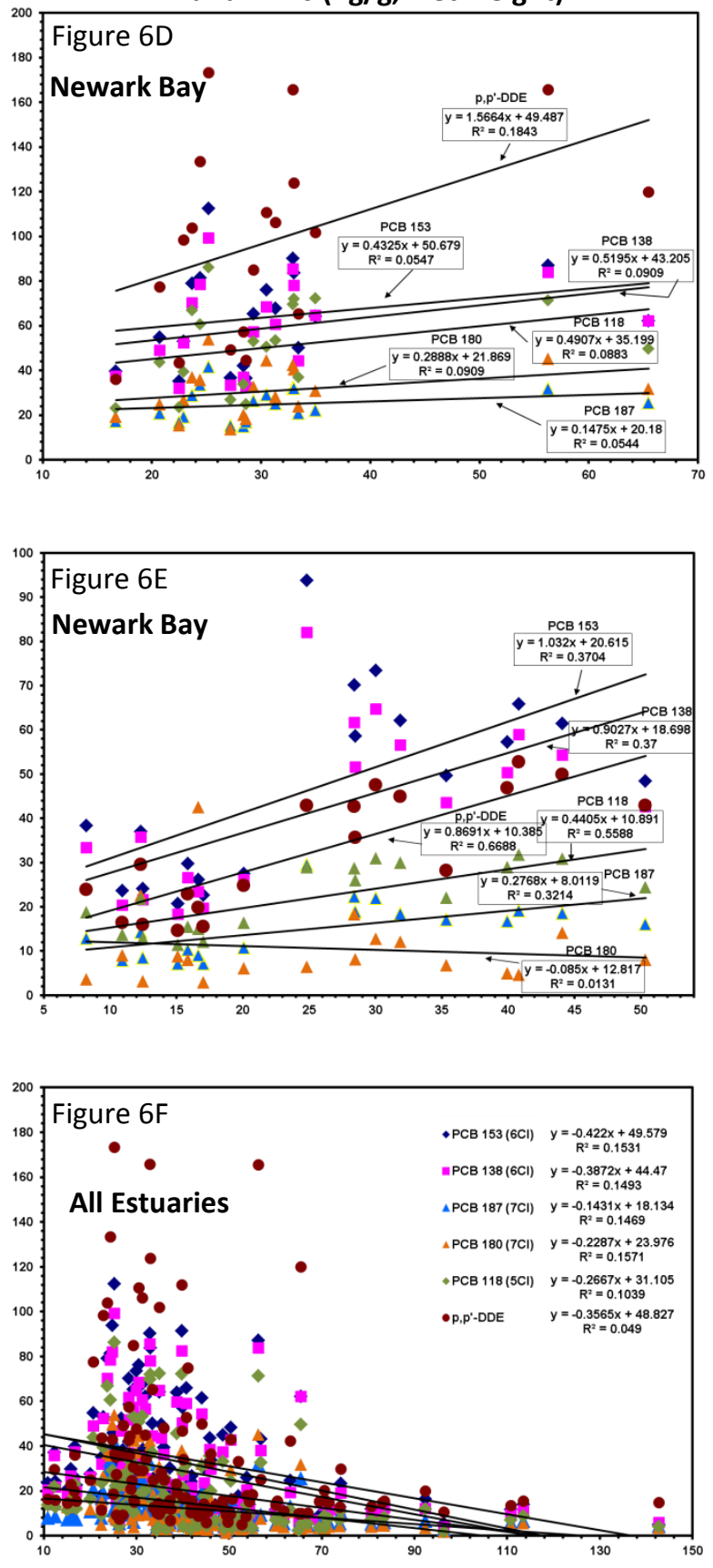

Fresh Weight of YOY Bluefish (g) 
Figure 7A

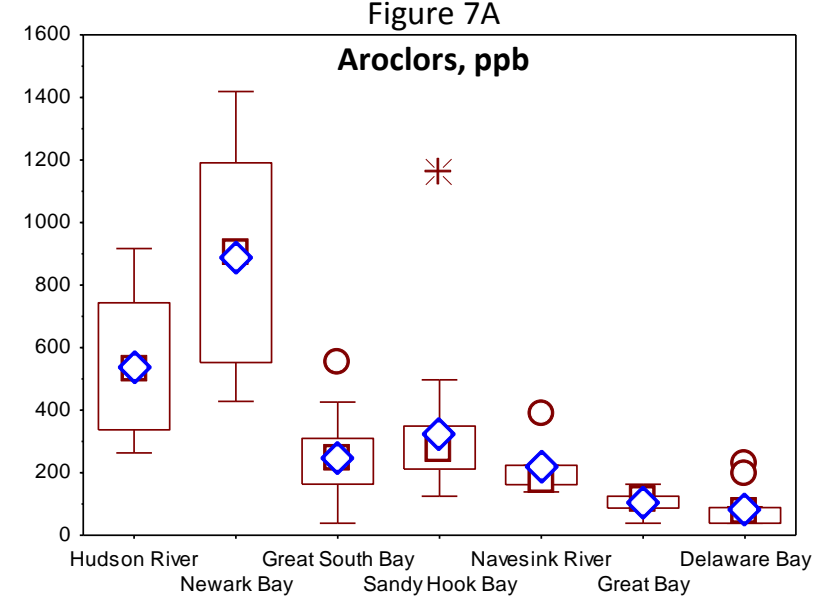

Figure 7B

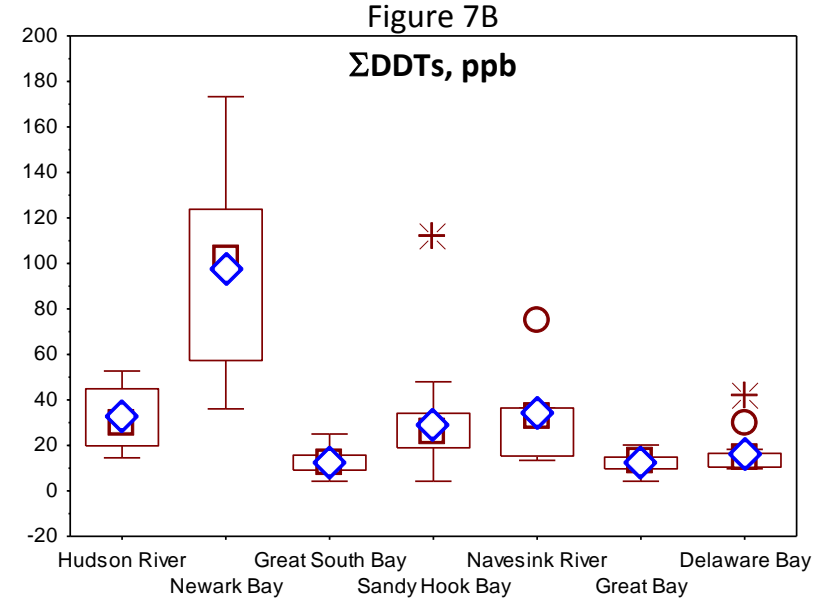

Figure 7C

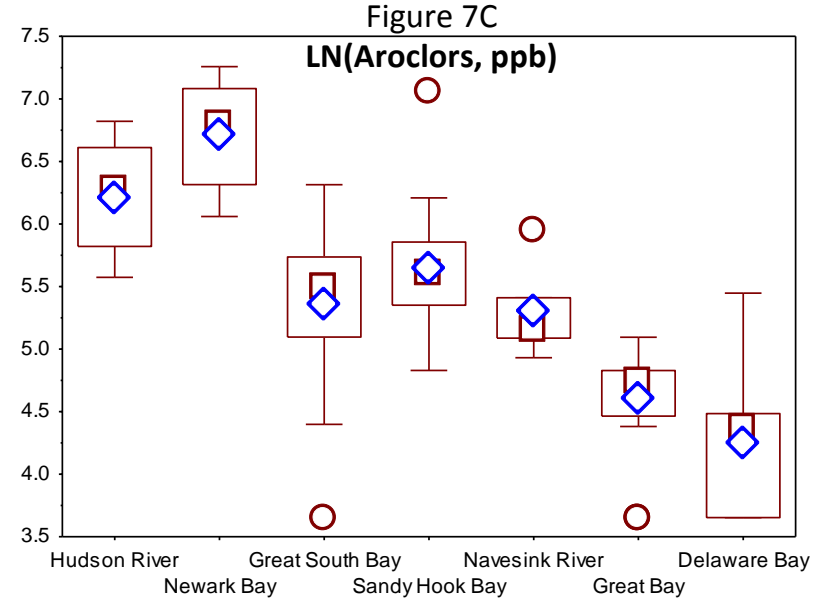

Figure 7D

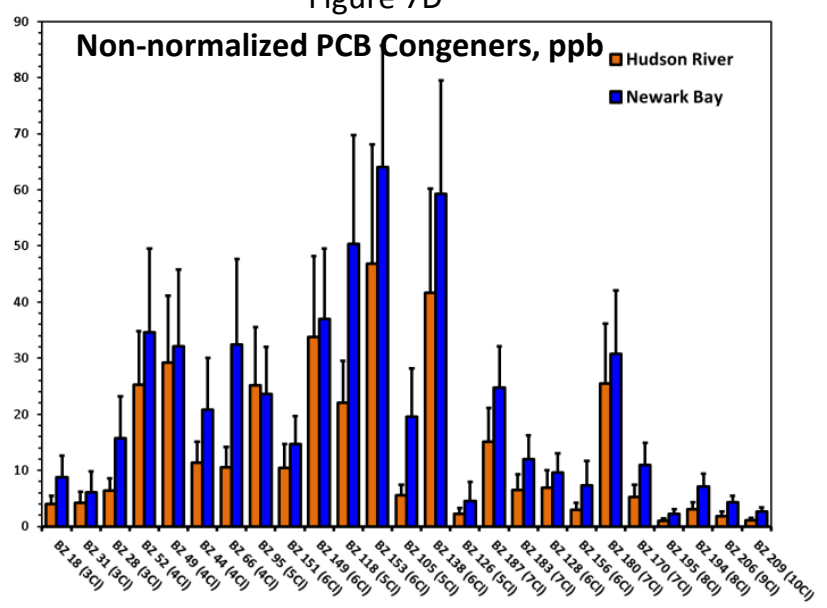

Figure 7E

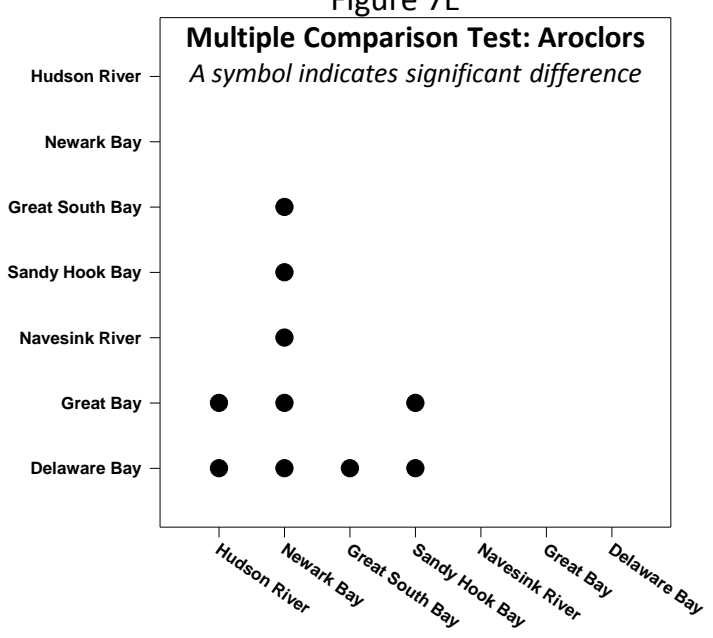

Figure 7F

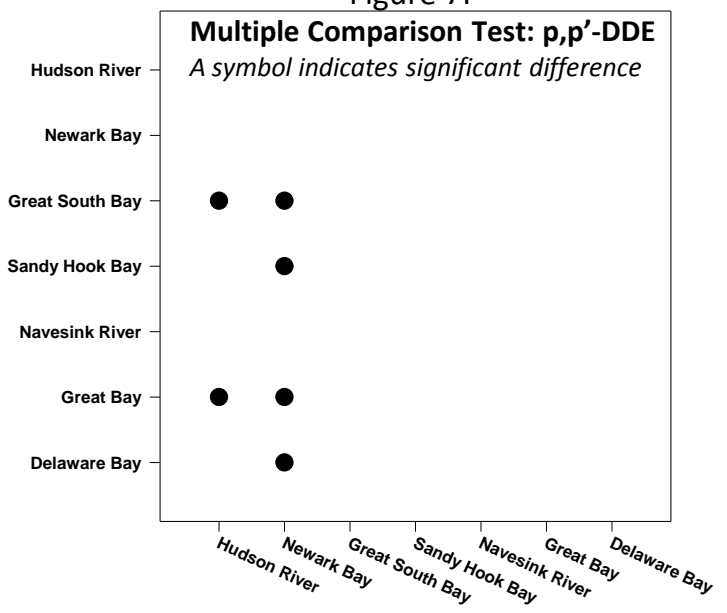

$\square$ Median $\square$ 25\%-75\% I Non-Outlier Range

O Outliers $*$ Extremes $\diamond$ Mean 
Figure 8

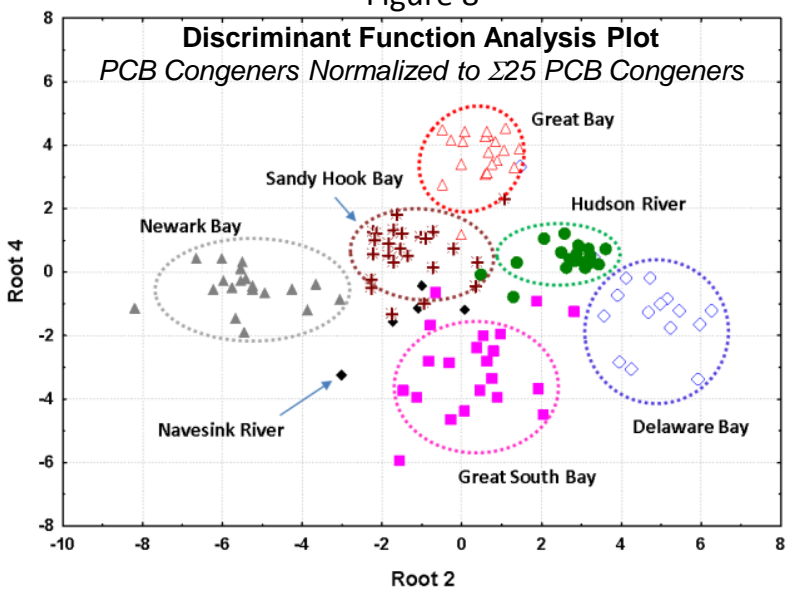


Table 1. Pearson product moment correlation coefficients $(R)$ for correlations between different physical and chemical parameters measured in YOY bluefish from different estuaries in the New York Bight

\begin{tabular}{|c|c|c|c|c|c|c|c|}
\hline Correlation Type/Location & $\begin{array}{c}\text { Hudson } \\
\text { River }\end{array}$ & $\begin{array}{c}\text { Newark } \\
\text { Bay }\end{array}$ & $\begin{array}{c}\text { Great } \\
\text { South Bay }\end{array}$ & $\begin{array}{c}\text { Sandy } \\
\text { Hook Bay }\end{array}$ & $\begin{array}{c}\text { Navesink } \\
\text { River }\end{array}$ & Great Bay & $\begin{array}{c}\text { Delaware } \\
\text { Bay }\end{array}$ \\
\hline Length - Weight & 0.9795 & 0.9329 & 0.9603 & 0.9590 & 0.9915 & 0.9253 & 0.9835 \\
\hline Length - Lipids & 0.5165 & 0.5002 & 0.4881 & 0.3287 & 0.6786 & 0.7449 & 0.0477 \\
\hline Weight - Lipids & 0.5350 & 0.7122 & 0.4321 & 0.3500 & 0.7168 & 0.7431 & 0.0295 \\
\hline Length - Fulton's Condition & 0.6274 & 0.0248 & 0.0107 & -0.1077 & 0.2883 & 0.4080 & 0.4638 \\
\hline Length - Allometric Condition & 0.6441 & 0.0435 & 0.0340 & -0.0819 & 0.3392 & 0.4170 & 0.4928 \\
\hline Weight - Fulton's Condition & 0.7094 & 0.3493 & 0.2741 & 0.1236 & 0.4060 & 0.7185 & 0.5252 \\
\hline Weight - Allometric Condition & 0.7241 & 0.3668 & 0.2963 & 0.1487 & 0.4543 & 0.7254 & 0.5523 \\
\hline Lipids - Fulton's Condition & 0.3294 & 0.6855 & -0.2430 & 0.2541 & 0.5135 & 0.4592 & 0.2295 \\
\hline Lipids - Allometric Condition & 0.3376 & 0.6947 & -0.2323 & 0.2638 & 0.5400 & 0.4651 & 0.2277 \\
\hline Aroclors - Weight & 0.6479 & 0.3413 & 0.1131 & -0.1379 & -0.6255 & 0.5291 & 0.0483 \\
\hline Aroclors - Length & 0.7097 & 0.3551 & 0.0538 & -0.1806 & -0.5974 & 0.5291 & 0.1166 \\
\hline Aroclors - Lipids & 0.4332 & 0.3866 & 0.2082 & 0.7160 & -0.8487 & 0.6521 & 0.7526 \\
\hline Aroclors - Fulton's Condition & 0.3205 & 0.1650 & 0.1371 & 0.1908 & -0.5440 & 0.1860 & 0.0397 \\
\hline Aroclors - Allometric Condition & 0.3348 & 0.1710 & 0.1383 & 0.1875 & -0.5664 & 0.1907 & 0.0438 \\
\hline DDTs - Weight & 0.7950 & 0.4135 & 0.3362 & -0.1330 & -0.8028 & 0.5797 & 0.1004 \\
\hline DDTs - Length & 0.8380 & 0.4527 & 0.3112 & -0.1806 & -0.8028 & 0.6521 & 0.1626 \\
\hline DDTs - Lipids & 0.5989 & 0.3265 & 0.4227 & 0.7046 & -0.2474 & 0.7030 & 0.8643 \\
\hline DDTs - Fulton's Condition & 0.3958 & 0.0648 & 0.0424 & 0.2418 & -0.0115 & 0.2368 & 0.1153 \\
\hline DDTs - Allometric Condition & 0.4122 & 0.0726 & 0.0495 & 0.2380 & -0.0604 & 0.2426 & 0.1197 \\
\hline Fulton's - Allometric Condition & 0.9998 & 0.9998 & 0.9997 & 0.9997 & 0.9986 & 1.0000 & 0.9995 \\
\hline Aroclors - DDTs & 0.9488 & 0.9441 & 0.8409 & 0.9844 & 0.3681 & 0.7958 & 0.9555 \\
\hline
\end{tabular}


Table 2. MDL corrected minimum, maximum, median, and average concentrations of individual PCB congeners, total PCBs, and Aroclor estimates in YOY bluefish in New York Bight estuaries; ng・g-1 wet weight

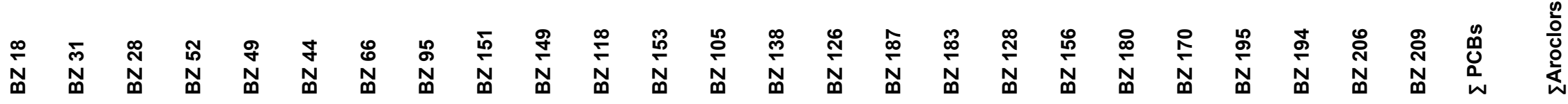

\section{Hudson River $(\mathbf{N}=19)$}

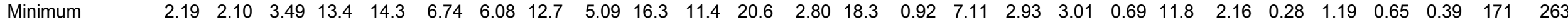

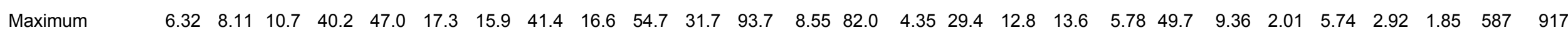

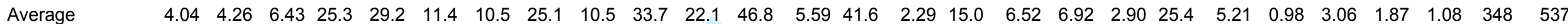

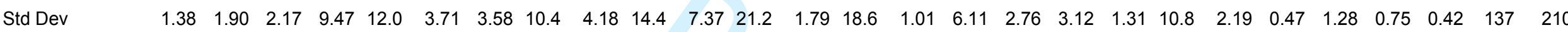

\section{Newark Bay $(\mathrm{N}=19)$}

Minimum

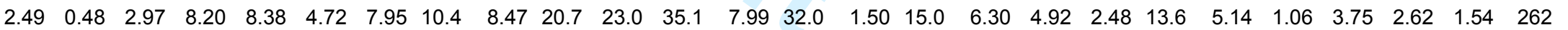

Maximum

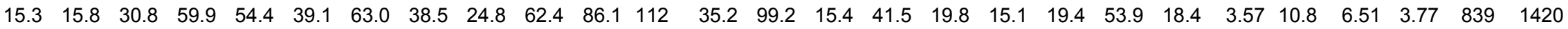

Average

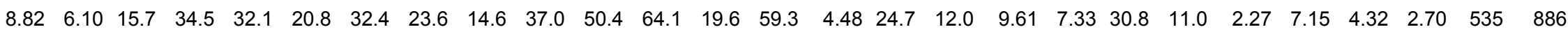

Std Dev

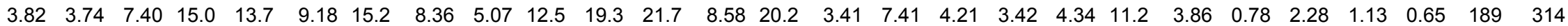

\section{Great South Bay $(\mathrm{N}=21)$}

Minimum

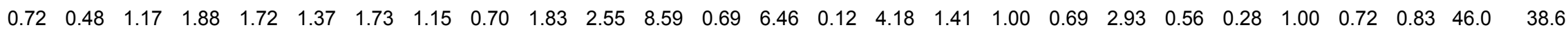

Maximum

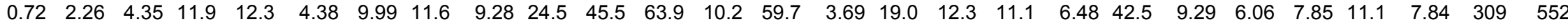

Average

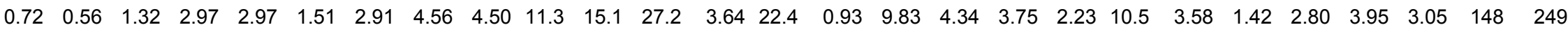

Std Dev

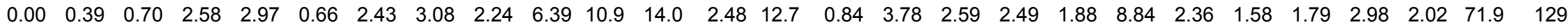


Table 2. MDL corrected minimum, maximum, median, and average concentrations of individual PCB congeners, total PCBs, and Aroclor estimates in YOY bluefish in New York Bight estuaries; ng•g-1 wet weight

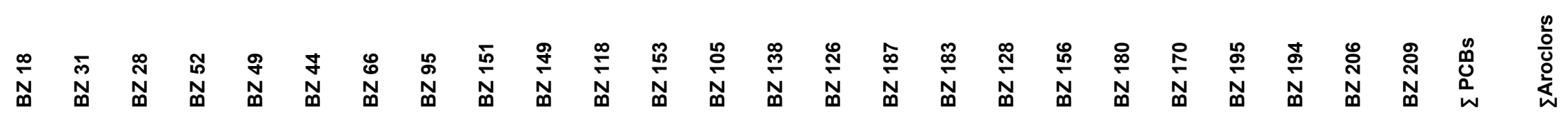

\section{Sandy Hook Bay $(\mathrm{N}=24)$}

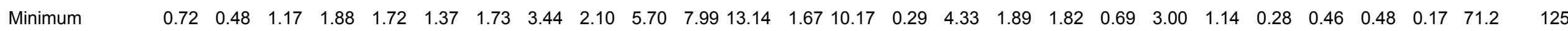

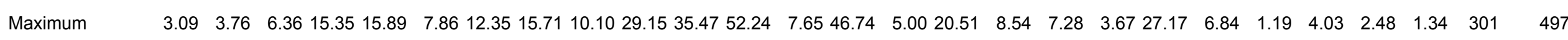

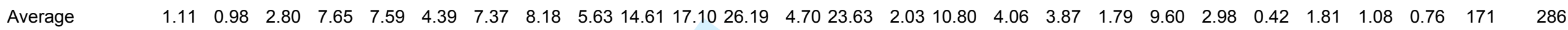

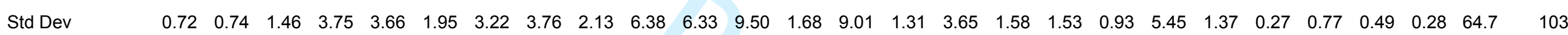

\section{Navesink River $(\mathbf{N}=5)$}

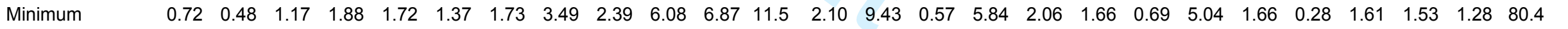

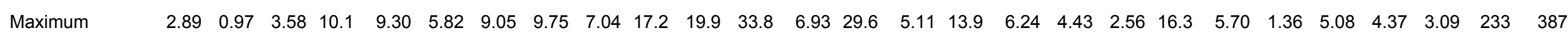

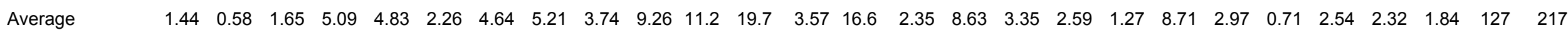

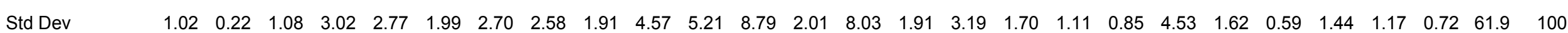

\section{Great Bay ( $N=20)$}

Minimum

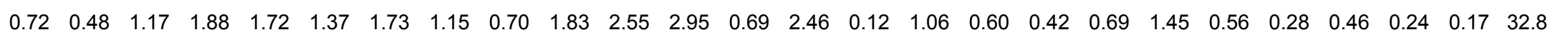

Maximum

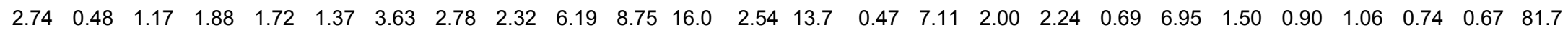

Average

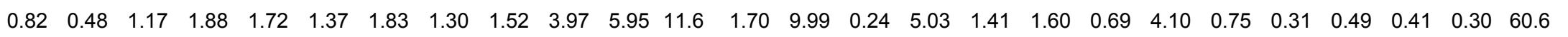

Std Dev

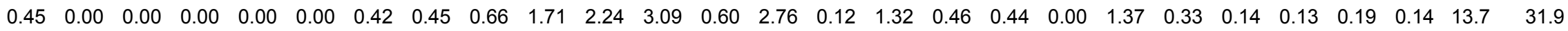


Table 2. MDL corrected minimum, maximum, median, and average concentrations of individual PCB congeners, total PCBs, and Aroclor estimates in YOY bluefish in New York Bight estuaries; ng・g-1 wet weight

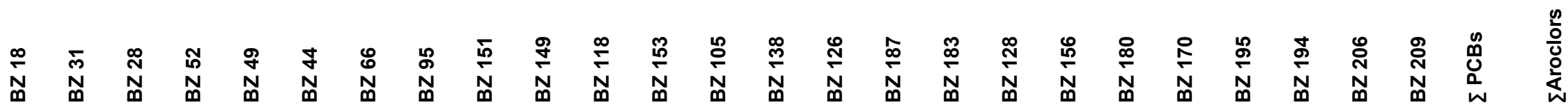

\section{Delaware Bay $(\mathbf{N}=16)$}

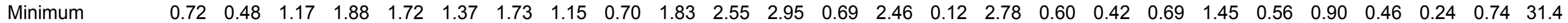
38.6

Maximum

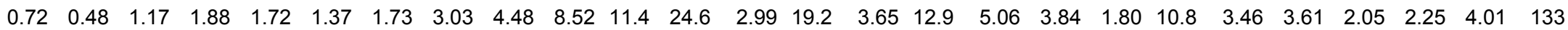

Average

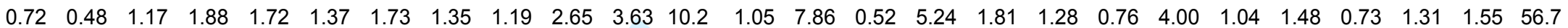

Std Dev

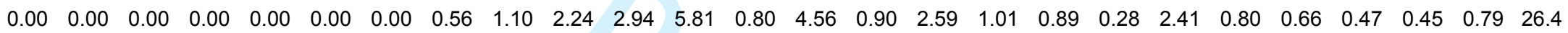

MDL determination using seven replicate aliquots of a homogenate of a single YOY bluefish from Newark Bay; $M D L=s t ~(t=3.143)$, $99 \%$ confidence limit

Average

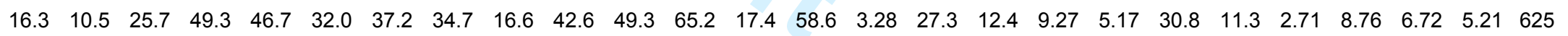


Table 3. MDL corrected minimum, maximum, median, and average concentrations of individual pesticides in YOY bluefish in New York Bight

estuaries; $n g \bullet g-1$ wet weight

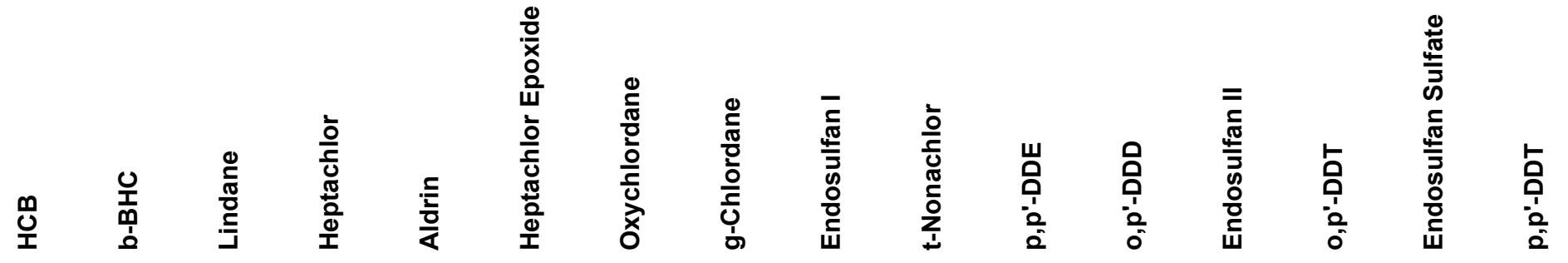

\section{Hudson River ( $\mathbf{N}=19$ )}

\begin{tabular}{|c|c|c|c|c|c|c|c|c|c|c|c|c|c|c|c|c|}
\hline Minimum & 0.16 & 0.19 & 0.02 & 0.02 & 0.03 & 0.09 & 0.13 & 0.51 & 14.2 & 1.80 & 14.5 & 1.68 & 0.18 & 1.30 & 0.21 & 0.44 \\
\hline Maximum & 0.37 & 0.44 & 0.46 & 0.37 & 0.09 & 1.68 & 1.26 & 1.48 & 46.9 & 4.23 & 52.7 & 5.87 & 2.36 & 7.17 & 7.40 & 4.88 \\
\hline Average & 0.18 & 0.22 & 0.11 & 0.10 & 0.04 & 1.11 & 0.52 & 0.84 & 28.7 & 2.82 & 32.5 & 3.62 & 0.36 & 4.03 & 3.34 & 1.56 \\
\hline Std Dev & 0.06 & 0.07 & 0.11 & 0.08 & 0.01 & 0.43 & 0.30 & 0.40 & 11.9 & 0.83 & 13.3 & 1.56 & 0.57 & 2.21 & 1.79 & 0.90 \\
\hline \multicolumn{17}{|c|}{ Newark Bay $(\mathrm{N}=19)$} \\
\hline Minimum & 0.37 & 0.19 & 0.04 & 0.21 & 0.03 & 0.09 & 0.54 & 2.30 & 18.7 & 4.30 & 36.1 & 3.73 & 1.29 & 1.30 & 0.21 & 1.94 \\
\hline Maximum & 4.62 & 1.54 & 1.33 & 0.98 & 0.51 & 3.90 & 3.81 & 11.8 & 65.7 & 23.7 & 173 & 17.2 & 5.83 & 7.80 & 1.29 & 6.76 \\
\hline Average & 2.29 & 0.69 & 0.29 & 0.53 & 0.26 & 2.17 & 2.21 & 7.92 & 38.6 & 15.0 & 97.9 & 8.61 & 2.70 & 4.04 & 0.80 & 4.47 \\
\hline Std Dev & 1.27 & 0.43 & 0.36 & 0.20 & 0.12 & 1.07 & 0.83 & 2.79 & 14.0 & 5.15 & 42.7 & 3.58 & 1.17 & 2.28 & 0.33 & 1.3 \\
\hline
\end{tabular}

Great South Bay $(\mathrm{N}=21)$

\begin{tabular}{|c|c|c|c|c|c|c|c|c|c|c|c|c|c|c|c|c|}
\hline Minimum & 0.16 & 0.19 & 0.02 & 0.02 & 0.03 & 0.09 & 0.13 & 0.51 & 1.46 & 0.70 & 4.26 & 0.43 & 0.18 & 1.30 & 0.21 & 0.44 \\
\hline Maximum & 0.16 & 0.19 & 0.13 & 0.18 & 0.20 & 0.69 & 0.63 & 0.51 & 21.8 & 3.30 & 25.0 & 3.39 & 4.17 & 3.52 & 12.2 & 1.46 \\
\hline Average & 0.16 & 0.19 & 0.05 & 0.06 & 0.05 & 0.25 & 0.25 & 0.51 & 8.92 & 1.64 & 12.4 & 1.70 & 1.17 & 1.56 & 1.27 & 0.64 \\
\hline Std Dev & 0 & 0.00 & 0.04 & 0.05 & 0.05 & 0.20 & 0.15 & 0.00 & 5.74 & 0.83 & 5.51 & 0.71 & 1.09 & 0.65 & 3.36 & 0.34 \\
\hline
\end{tabular}


Table 3. MDL corrected minimum, maximum, median, and average concentrations of individual pesticides in YOY bluefish in New York Bight estuaries; ng•g-1 wet weight

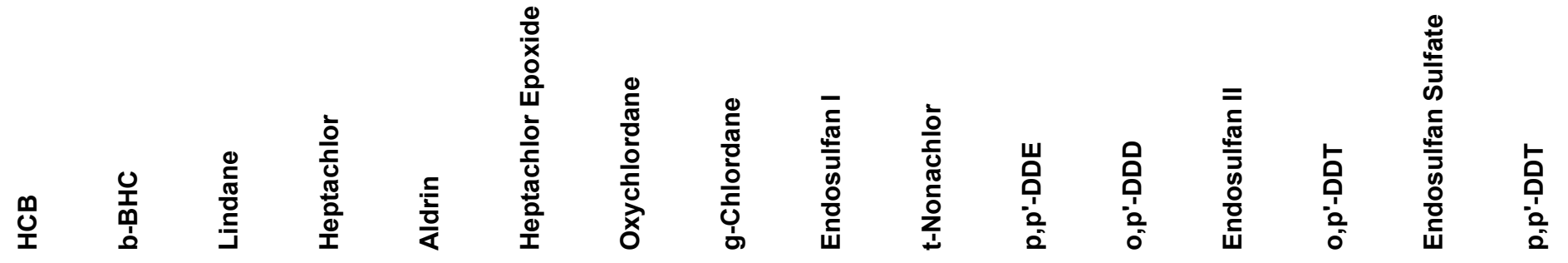

\section{Sandy Hook Bay $(\mathrm{N}=24)$}

\begin{tabular}{|c|c|c|c|c|c|c|c|c|c|c|c|c|c|c|c|c|}
\hline Minimum & 0.16 & 0.19 & 0.02 & 0.02 & 0.03 & 0.09 & 0.32 & 0.51 & 1.46 & 1.54 & 4.26 & 1.00 & 0.18 & 1.30 & 0.21 & 0.44 \\
\hline Maximum & 1.45 & 2.28 & 2.31 & 1.31 & 0.70 & 2.00 & 2.11 & 2.03 & 35.66 & 4.99 & 47.97 & 5.69 & 1.74 & 5.98 & 6.91 & 3.23 \\
\hline Average & 0.38 & 0.39 & 0.31 & 0.18 & 0.06 & 0.70 & 0.77 & 1.12 & 14.48 & 3.14 & 25.54 & 2.31 & 0.71 & 2.04 & 1.36 & 1.15 \\
\hline Std Dev & 0.31 & 0.54 & 0.49 & 0.36 & 0.14 & 0.72 & 0.35 & 0.46 & 9.12 & 0.80 & 10.01 & 1.25 & 0.46 & 1.53 & 1.85 & \\
\hline
\end{tabular}

\section{Navesink River $(\mathbf{N}=5)$}

$\begin{array}{lcccccccccccccccc}\text { Minimum } & 0.16 & 0.19 & 0.02 & 0.06 & 0.03 & 0.40 & 0.52 & 0.51 & 1.46 & 2.76 & 13.4 & 1.17 & 0.41 & 1.30 & 0.21 & 0.44 \\ \text { Maximum } & 0.8 & 0.19 & 1.41 & 0.28 & 0.23 & 1.20 & 1.41 & 3.38 & 8.92 & 7.93 & 74.8 & 2.12 & 3.04 & 1.30 & 0.75 & 5.09 \\ \text { Average } & 0.62 & 0.19 & 0.54 & 0.16 & 0.09 & 0.66 & 0.85 & 1.98 & 5.81 & 5.53 & 34.6 & 1.50 & 1.25 & 1.30 & 0.32 & 1.82 \\ \text { Std Dev } & 0.26 & 0.00 & 0.61 & 0.08 & 0.09 & 0.32 & 0.35 & 1.15 & 2.74 & 2.37 & 24.7 & 0.39 & 1.10 & 0.00 & 0.24 & 2.08\end{array}$

\section{Great Bay $(\mathrm{N}=20)$}

\begin{tabular}{|c|c|c|c|c|c|c|c|c|c|c|c|c|c|c|c|}
\hline Minimum & 0.16 & 0.19 & 0.02 & 0.02 & 0.03 & 0.18 & 0.13 & 0.51 & 1.46 & 0.70 & 4.26 & 0.43 & 0.18 & 1.30 & 0.21 \\
\hline Maximum & 0.78 & 3.04 & 1.62 & 0.14 & 0.03 & 0.95 & 0.71 & 0.51 & 5.89 & 3.35 & 20.2 & 1.49 & 0.50 & 1.30 & 1.56 \\
\hline Average & 0.21 & 0.44 & 0.29 & 0.04 & 0.03 & 0.42 & 0.24 & 0.51 & 3.75 & 1.39 & 12.3 & 0.91 & 0.20 & 1.30 & 1.02 \\
\hline Std Dev & 0.15 & 0.66 & 0.36 & 0.03 & 0.00 & 0.19 & 0.15 & 0.00 & 1.43 & 0.70 & 3.51 & 0.35 & 0.07 & 0.00 & 0.33 \\
\hline
\end{tabular}


Table 3. MDL corrected minimum, maximum, median, and average concentrations of individual pesticides in YOY bluefish in New York Bight

estuaries; ng・g-1 wet weight

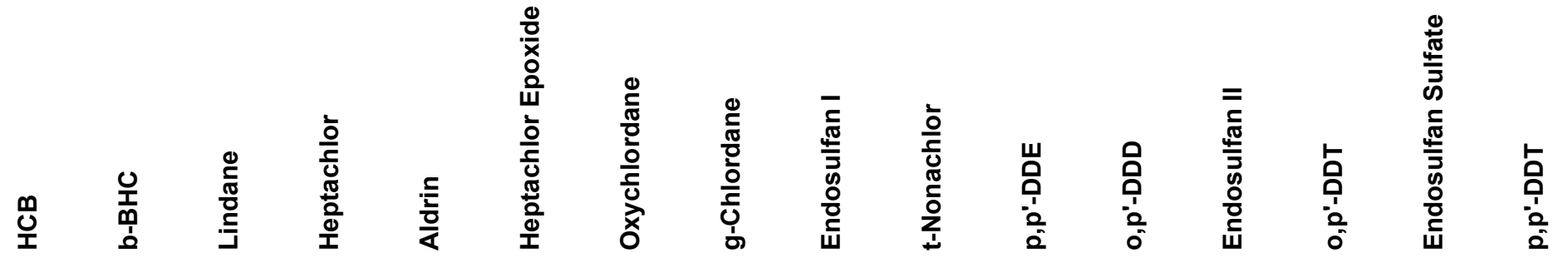

\section{Delaware Bay $(\mathrm{N}=16)$}

$\begin{array}{lcccccccccccccccc}\text { Minimum } & 0.16 & 0.19 & 0.02 & 0.02 & 0.03 & 0.09 & 0.13 & 0.51 & 1.46 & 0.70 & 9.74 & 0.43 & 0.18 & 1.30 & 0.57 & 0.44 \\ \text { Maximum } & 1.18 & 0.98 & 0.22 & 0.39 & 0.34 & 2.01 & 0.61 & 1.88 & 7.38 & 4.59 & 42.1 & 6.73 & 0.18 & 2.99 & 3.88 & 3.14 \\ \text { Average } & 0.22 & 0.31 & 0.09 & 0.11 & 0.07 & 0.71 & 0.22 & 0.60 & 1.83 & 1.07 & 16.1 & 1.68 & 0.18 & 1.41 & 1.21 & 0.67 \\ \text { Std Dev } & 0.26 & 0.24 & 0.07 & 0.10 & 0.09 & 0.53 & 0.16 & 0.34 & 1.48 & 1.07 & 8.50 & 1.49 & 0.00 & 0.42 & 0.80 & 0.68\end{array}$

MDL determination using seven replicate aliquots of a homogenate of a single YOY bluefish from Newark Bay; MDL = st ( $t=3.143$ ), $99 \%$ confidence limit

\begin{tabular}{|c|c|c|c|c|c|c|c|c|c|c|c|c|c|c|c|c|}
\hline Average & 3.23 & 1.38 & 0.28 & 0.56 & 0.32 & 2.72 & 3.42 & 11.31 & 44.14 & 16.75 & 94.35 & 10.65 & 2.88 & 6.62 & 0.96 & 8.16 \\
\hline SD & 0.10 & 0.12 & 0.01 & 0.02 & 0.02 & 0.05 & 0.08 & 0.33 & 0.93 & 0.44 & 2.71 & 0.27 & 0.11 & 0.83 & 0.13 & 0.28 \\
\hline$\%$ RSD & 3.15 & 8.85 & 4.14 & 2.74 & 6.33 & 2.01 & 2.34 & 2.89 & 2.11 & 2.64 & 2.87 & 2.58 & 3.98 & 12.55 & 13.83 & 3.40 \\
\hline MDL & 0.32 & 0.38 & 0.04 & 0.05 & 0.06 & 0.17 & 0.25 & 1.03 & 2.92 & 1.39 & 8.52 & 0.86 & 0.36 & 2.61 & 0.42 & 0.87 \\
\hline
\end{tabular}


Table 4. Examination of decrease in \%RSD of concentrations of PCB congeners after PCB 153 normalization

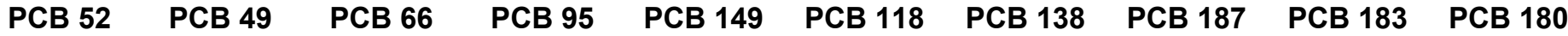

\section{\% RSD Before PCB153 Normalization}

\begin{tabular}{|c|c|c|c|c|c|c|c|c|c|c|}
\hline Hudson River & 37.5 & 41.0 & 33.9 & 41.4 & 42.8 & 33.4 & 44.6 & 40.6 & 42.2 & 42.4 \\
\hline Newark Bay & 43.5 & 42.7 & 47.0 & 35.4 & 33.9 & 38.4 & 34.1 & 29.9 & 35.1 & 36.4 \\
\hline Great South Bay & 91.6 & 103 & 75.7 & 62.4 & 55.5 & 69.3 & 56.7 & 38.4 & 59.7 & 83.8 \\
\hline Sandy Hook Bay & 85.8 & 88.1 & 80.8 & 83.4 & 71.8 & 66.2 & 57.1 & 54.3 & 55.9 & 73.0 \\
\hline Navesink River & 51.3 & 46.2 & 47.1 & 49.4 & 49.3 & 46.6 & 48.4 & 37.0 & 50.9 & 52.0 \\
\hline Great Bay & 33.0 & 35.2 & 29.8 & 28.8 & 23.8 & 22.5 & 25.5 & 23.1 & 23.3 & 30.7 \\
\hline Delaware Bay & 60.9 & 60.7 & 72.6 & 68.3 & 61.0 & 67.4 & 56.7 & 49.6 & 53.4 & 56.5 \\
\hline \multicolumn{11}{|c|}{ \% RSD After PCB153 Normalization } \\
\hline Hudson River & 16.3 & 14.6 & 20.5 & 13.8 & 9.91 & 14.4 & 2.91 & 8.65 & 5.29 & 12.1 \\
\hline Newark Bay & 29.0 & 27.3 & 32.7 & 19.4 & 9.73 & 14.2 & 4.66 & 9.50 & 8.59 & 9.21 \\
\hline Great South Bay & 49.7 & 56.7 & 32.3 & 26.0 & 23.7 & 18.5 & 5.83 & 31.4 & 41.1 & 57.6 \\
\hline Sandy Hook Bay & 29.3 & 28.0 & 31.4 & 20.1 & 13.7 & 16.8 & 7.83 & 9.62 & 9.70 & 23.4 \\
\hline Navesink River & 27.9 & 26.1 & 23.1 & 27.9 & 13.5 & 10.1 & 3.22 & 8.71 & 8.06 & 7.01 \\
\hline Great Bay & 32.2 & 30.7 & 29.7 & 29.6 & 30.7 & 28.9 & 2.94 & 6.90 & 6.14 & 12.2 \\
\hline Delaware Bay & 27.5 & 39.0 & 32.3 & 30.4 & 12.9 & 31.7 & 15.9 & 20.0 & 38.1 & 23.6 \\
\hline \multicolumn{11}{|c|}{ Net Decrease in \%RSD After PCB153 Normalization } \\
\hline Hudson River & 21.1 & 26.3 & 13.4 & 27.7 & 32.9 & 19.0 & 41.7 & 32.0 & 37.0 & 30.2 \\
\hline Newark Bay & 14.4 & 15.3 & 14.3 & 16.0 & 24.2 & 24.2 & 29.4 & 20.4 & 26.5 & 27.2 \\
\hline Great South Bay & 41.9 & 46.3 & 43.5 & 36.4 & 31.9 & 50.8 & 50.9 & 7.09 & 18.6 & 26.2 \\
\hline Sandy Hook Bay & 56.5 & 60.1 & 49.3 & 63.3 & 58.1 & 49.4 & 49.3 & 44.7 & 46.2 & 49.5 \\
\hline Navesink River & 23.4 & 20.0 & 24.0 & 21.5 & 35.8 & 36.4 & 45.2 & 28.3 & 42.8 & 45.0 \\
\hline Great Bay & 0.808 & 4.527 & 0.145 & -0.804 & -6.92 & -6.35 & 22.6 & 16.2 & 17.2 & 18.5 \\
\hline Delaware Bay & 33.3 & 21.7 & 40.3 & 37.9 & 48.1 & 35.7 & 40.9 & 29.6 & 15.3 & 32.9 \\
\hline
\end{tabular}


Table 5. Dicriminant function analysis (DFA): means of canonical variables test for PCB congeners in bluefish normalized to the sum of 25 PCB congeners

\begin{tabular}{lrrrr} 
Location & \multicolumn{3}{c}{ Means of Canonical Variables } \\
& Root 1 & Root 2 & Root 3 & Root 4 \\
Delaware Bay & 4.0567 & 4.57900 & 4.10088 & -1.08250 \\
Great Bay & 4.4459 & 0.50028 & -0.99887 & 3.70730 \\
Hudson River & -10.0920 & 2.62615 & -0.40478 & 0.44102 \\
Great South Bay & 2.9980 & 0.33864 & -2.82073 & -3.02248 \\
Navesink River & -0.1071 & -1.35150 & -1.72615 & -1.50734 \\
Newark Bay & -1.3938 & -5.37777 & 2.87969 & -0.50536 \\
Sandy Hook Bay & 0.0827 & -1.30595 & -1.03308 & 0.64189
\end{tabular}

